\title{
Northern Hemisphere storminess in the Norwegian Earth System Model (NorESM1-M)
}

\author{
Erlend M. Knudsen ${ }^{1,2, a}$ and John E. Walsh ${ }^{3}$ \\ ${ }^{1}$ Geophysical Institute, University of Bergen, P.O. Box 7803, 5020 Bergen, Norway \\ ${ }^{2}$ Bjerknes Centre for Climate Research, Bergen, Norway \\ ${ }^{3}$ International Arctic Research Center, University of Alaska Fairbanks, \\ 930 Koyukuk Drive, Fairbanks, Alaska 99775-7340, USA \\ anow at: Institute for Geophysics and Meteorology, University of Cologne, \\ Albertus-Magnus-Platz, 50923 Köln, Germany \\ Correspondence to: Erlend M. Knudsen (eknudsen@uni-koeln.de)
}

Received: 17 November 2014 - Published in Geosci. Model Dev. Discuss.: 16 December 2014 Revised: 10 June 2016 - Accepted: 20 June 2016 - Published: 7 July 2016

\begin{abstract}
Metrics of storm activity in Northern Hemisphere high and midlatitudes are evaluated from historical output and future projections by the Norwegian Earth System Model (NorESM1-M) coupled global climate model. The European Re-Analysis Interim (ERA-Interim) and the Community Climate System Model (CCSM4), a global climate model of the same vintage as NorESM1-M, provide benchmarks for comparison. The focus is on the autumn and early winter (September through December) - the period when the ongoing and projected Arctic sea ice retreat is the greatest. Storm tracks derived from a vorticity-based algorithm for storm identification are reproduced well by NorESM1-M, although the tracks are somewhat better resolved in the higherresolution ERA-Interim and CCSM4. The tracks show indications of shifting polewards in the future as climate changes under the Representative Concentration Pathway (RCP) forcing scenarios. Cyclones are projected to become generally more intense in the high latitudes, especially over the Alaskan region, although in some other areas the intensity is projected to decrease. While projected changes in track density are less coherent, there is a general tendency towards less frequent storms in midlatitudes and more frequent storms in high latitudes, especially the Baffin Bay/Davis Strait region in September. Autumn precipitation is projected to increase significantly across the entire high latitudes. Together with the projected loss of sea ice and increases in storm intensity and sea level, this increase in precipitation implies a greater vulnerability to coastal flooding and erosion, especially in the
\end{abstract}

Alaskan region. The projected changes in storm intensity and precipitation (as well as sea ice and sea level pressure) scale generally linearly with the RCP value of the forcing and with time through the 21 st century.

\section{Introduction}

The Arctic climate has undergone substantial change in recent decades, and these changes are projected to continue into the future. Much of the effort to diagnose and project Arctic change has focused on temperature, sea ice and precipitation. However, climate-driven changes in storms are arguably more important considerations for Arctic residents, as well as for the heat and moisture budgets of the atmosphere. The impacts of storms are magnified by the loss of sea ice, which increases wave activity, coastal flooding and erosion and also increases the risks of vessel icing in waters newly accessible for marine transport and for other offshore activities (AMAP, 2005).

Analyses of observational data have produced mixed results on trends of high-latitude storminess. In earlier studies, Zhang et al. (2004) found an increase of Arctic cyclone activity, while McCabe et al. (2001) reported northward shifts of storm tracks over the Northern Hemisphere (NH) over the last several decades of the 20th century. Wang et al. (2006) detected a northward shift of cyclone activity, primarily during winter, over Canada during 1953-2002, and this merid- 
ional shift was confirmed more generally in a more recent study by the same group (Wang et al., 2013). The recent U.S. National Climate Assessment (Melillo et al., 2014) points to a poleward shift of storm tracks over the United States during recent decades. However, Mesquita et al. (2010) found that temporal trends of cyclones in the North Pacific Ocean have generally been weak over the 60-year period ending 2008 . The U.S. Global Change Research Program (Karl et al., 2009) points to an increase of storminess on the northern Alaskan coast and to associated risks of flooding and coastal erosion along with expected sea level rise. Since any increases of coastal flooding and erosion are also related to retreating sea ice, storms in coastal areas of the Arctic can pose increasing risks regardless of whether storm activity is changing.

Previous work addressing cyclone-sea ice linkages has shown increasing cyclone strength occurring with a retreating September sea ice edge, though no relationship with cyclone counts was found (Simmonds and Keay, 2009). Increasing amounts of open water in the Arctic enhance exchanges of heat, moisture and momentum between the surface and atmosphere as a cyclone passes. Depending on the track of a cyclone, these additional fluxes can impact cyclone development. Two studies, one an evaluation of midlatitude marine cyclones (Kuo et al., 1991) and the other a case study of summer Arctic cyclones (Lynch et al., 2003), found surface energy flux input to be most important in the initial formation stages of the cyclone. Inputs in the later stages of the cyclone life cycle showed little impact. Furthermore, two case studies of Arctic cyclones found that increased surface energy fluxes in the later stages of the cyclone were not enough to overcome the large-scale dynamics (Long and Perrie, 2012; Simmonds and Rudeva, 2012). However, the former study indicated increased maximum wind speeds as the cyclone studied moved over open water, primarily through enhanced momentum exchange between the surface and atmosphere compared to what would occur over sea ice. These results indicate that the cyclone track is rather important as to whether or not changing surface conditions will significantly impact cyclone development.

In assessing linkages between recent Arctic warming and changes in storminess, polar amplification is a key consideration because it is associated with changes in baroclinicity. The polar amplification, due in part to the reduction of sea ice and snow cover, manifests itself in the approximately 2 -fold difference between recent changes in the Arctic and global mean temperatures (e.g. Bekryaev et al., 2010; AMAP, 2011). The warming of the Arctic has contributed to, and been increased by, the loss of sea ice (Stocker et al., 2013). Other important factors contributing to polar amplification appear to be the lapse rate feedback, the increase in atmospheric humidity and the fact that long-wave radiation to space increases less under global warming in the cold polar regions than in the tropics (the so-called Planck Effect; Pithan and Mauritsen, 2014). Impacts of sea ice loss and
Arctic warming on the atmospheric circulation in the high and midlatitudes have been suggested by the studies of Overland and Wang (2010), Francis and Vavrus (2012) and Cohen et al. (2012), although the robustness of the midlatitude impacts has been questioned (Barnes, 2013; Barnes et al., 2014; Screen and Simmonds, 2013). Whether or not a large-scale signal of Arctic warming and sea ice loss has yet emerged from the noise of internal variability, climate models project continued Arctic warming and sea ice loss through the 21st century, increasing the likelihood of associated changes in the large-scale circulation. Sea ice is therefore one of our foci in the assessment of changes in model-simulated storminess through the 21 st century.

Global climate models are arguably the best tools for identifying externally forced signals (greenhouse gases and aerosols) in storm activity. They simulate polar amplification that is quite consistent with recent observed trends (AMAP, 2011, Fig. 3.1). In this study, we seek to validate the storm track components of two state-of-the-art global climate models over midlatitudes and high latitudes of the NH. This is done through a comparison to a reanalysis data set. The models are the Norwegian Earth System Model version 1 with intermediate resolution (NorESM1-M) and the Community Climate System Model version 4 (CCSM4). The simulations examined here were performed as part of the Coupled Model Intercomparison Project phase 5 (CMIP5; Taylor et al., 2012). After assessing the models' ability to capture the primary cyclone characteristics over a recent historical period, we compare the future changes of high and midlatitude storms through the late 21 st century. This evaluation is both a comparison between the time periods for each model and a model intercomparison on diverging changes towards the late 21 st century. The primary metrics of storm activity here are frequency (track density) and intensity (mean intensity).

The impacts of a warming climate on high-latitude storms are difficult to anticipate. Both models undergo Arcticamplified warming at low levels associated with significant loss of sea ice cover in the 21 st century simulations examined here. Using an idealized, moist general circulation model, O'Gorman and Schneider (2008) showed that changes in the atmospheric thermal structure affecting the mean available potential energy can lead to changes in eddy kinetic energy. The way in which this notion will play out in actuality with a warmer Arctic and less sea ice is uncertain. On the one hand, the increased surface fluxes of heat and moisture might be expected to fuel more and stronger storms. On the other hand, the polar amplification decreases the low-level meridional temperature gradients, reducing the potential for storm activity. Nevertheless, because upper-level temperatures show greater increases in the tropics than in the polar regions, upper-level meridional temperature gradients actually increase (Harvey et al., 2015). Hence, the net effect on baroclinicity cannot be simply related to baroclinic disturbances such as extratropical cyclones (Ulbrich et al., 2009). More- 
over, the Arctic amplification affects the variability of the jet stream, which is directly linked to the vertically integrated meridional temperature gradient via the thermal wind equation. Barnes and Screen (2015) provided a diagnostic assessment of these connections. Here, the model set-up implies that impacts of Arctic warming, sea ice loss and changes in surface fluxes and temperature gradients are implicit in our results.

The paper is organized as follows: Sect. 2 describes the models, reanalysis and methods used in this study. Section 3 presents the results of the comparison with the historical reanalysis and an overview of the primary changes in the storm metrics over the 21 st century, followed by a discussion of the changes in the context of earlier studies and possible future implications. Finally, Sect. 4 concludes with a summary of the results, uncertainties and ideas for future work.

\section{Data sets and methods}

\subsection{Models}

The present study uses two global climate models, NorESM1-M and CCSM4, both of which are coupled atmosphere-ocean-land-sea ice models. In keeping with the theme of this special issue, we emphasize NorESM1-M and its simulations. The output of CCSM4, which has somewhat finer resolution, is also examined since its storm simulations can serve as a benchmark for NorESM1-M. The following is a more complete description of NorESM1-M.

NorESM1-M is a global, coupled model system for the physical climate system. It is a joint model effort of eight Norwegian research institutions, building on and replacing the Bergen Climate Model (BCM; Furevik et al., 2003) as the Norwegian CMIP model in the Intergovernmental Panel on Climate Change (IPCC) assessment reports.

NorESM1-M is described in more detail in Bentsen et al. (2013) and Iversen et al. (2013). It is based on CCSM4 and the Community Earth System Model (CESM) projects at the National Center for Atmospheric Research (NCAR) on behalf of the University Corporation for Atmospheric Research (UCAR; Gent et al., 2011). However, NorESM1-M differs from CCSM4 in the following components: its own developed code for chemistry-aerosol-cloud-radiation interactions in the atmospheric module (CAM4-Oslo; Kirkevåg et al., 2013); an isopycnic coordinate ocean general circulation model developed in Bergen (e.g. Drange et al., 2005) and originating from the Miami Isopycnic Coordinate Ocean Model (MICOM; Bleck et al., 1992) and a biogeochemical ocean module from the HAMburg Ocean Carbon Cycle (HAMOCC) model developed at the Max Planck Institute for Meteorology (MPI) in Hamburg (Maier-Reimer, 1993; Maier-Reimer et al., 2005) and adapted to the isopycnic ocean model framework (Tjiputra et al., 2010).
In this study, the first version of NorESM with intermediate resolution is presented. Known formally as NorESM1-M, the model has a horizontal resolution of approximately $2^{\circ}$ for atmosphere and land components and $1^{\circ}$ for ocean and ice components. Its vertical resolution consists of $26 \mathrm{lev}-$ els of hybrid sigma-pressure coordinates with a model top of $2.9 \mathrm{hPa}$. For brevity, the model is denoted as NorESM throughout this paper.

CCSM4 has twice the horizontal resolution of NorESM, with $1.25^{\circ} \times 0.90^{\circ}$ horizontal resolution and 26 vertical layers. It is developed at UCAR and maintained by NCAR. Described in more detail by Gent et al. (2011), CCSM4 consists of five geophysical models: atmosphere (Community Atmosphere Model; CAM4), land (Community Land Model; CLM4), ocean (Parallel Ocean Program; POP2), land ice (GLC), sea ice (Los Alamos Sea Ice Model/Community Ice CodE; CICE4), and a coupler (CPL7) that coordinates the models and sends information between them. de Boer et al. (2012) and other accompanying papers in the same CCSM4 Special Issue of the Journal of Climate assess the performance of CCSM4. For the remainder of this paper, CCSM4 will be denoted as CCSM for brevity. Apart from differences in the realizations, systematic divergence between the two models highlights the role of the ocean, sea ice and atmospheric chemistry in the climate system with other model components being similar.

Only one ensemble member of each model (NorESM: rli1p1, CCSM: r6ilp1) is examined in the present study because only these ensemble members meet our required criteria for temporal resolution (6-hourly output is needed for cyclone tracking) and choice of scenarios. Because of this data limitation there is only a thin base for overall evaluation of storminess in CMIP5 models. However, we use multidecadal time slices in order to minimize the effects of internal variations, which account for differences across ensemble members of simulations by any one model. Moreover, Walsh et al. (2008) found that the spread within ensemble members of a single model is much smaller than inter-model spread when Arctic-averaged temperatures are compared.

\subsection{Reanalysis}

The analysis involves three time periods of 27 years each and two Representative Concentration Pathways (RCPs). For the historical time period, 1979-2005, NorESM and CCSM are compared to the European Re-Analysis Interim (ERAInterim; here abbreviated ERA-I) data set (Dee et al., 2011). ERA-I is a high-resolution reanalysis set in space and time, and is well suited for the northern regions (Jakobson et al., 2012; Chung et al., 2013), especially for storm tracking (Hodges et al., 2011; Zappa et al., 2013a).

Reanalyses have great difficulty capturing mesoscale lowpressure systems (including "polar lows"), which have typical scales of 200-300 km and lifetimes generally shorter than 2 days (Condron and Renfrew, 2013). In a comparison of cy- 
Table 1. Decadal mean Arctic sea ice extent monthly averages for 2000s, 2050s and 2090s and changes for the two latter decades compared to the former, following the RCP8.5 scenario. 2000s: first number within row from NSIDC; second number within row from NorESM; third number within row from CCSM. Other decades: first number within each row from NorESM; second number within each row from CCSM. Unit is $10^{6} \mathrm{~km}^{2}$.

\begin{tabular}{|c|c|c|c|c|c|c|c|c|c|c|c|c|}
\hline Decade & Jan & Feb & Mar & Apr & May & Jun & Jul & Aug & Sep & Oct & Nov & Dec \\
\hline & 14.1 & 14.9 & 15.1 & 14.3 & 13.1 & 11.5 & 9.1 & 6.5 & 5.7 & 8.3 & 10.4 & 12.6 \\
\hline \multirow[t]{2}{*}{$2000 \mathrm{~s}$} & 13.1 & 14.0 & 14.7 & 14.2 & 13.3 & 11.7 & 10.2 & 9.0 & 7.8 & 9.2 & 10.6 & 12.1 \\
\hline & 12.4 & 13.0 & 13.2 & 12.8 & 11.9 & 10.4 & 8.7 & 6.6 & 5.5 & 7.3 & 8.8 & 10.8 \\
\hline \multirow[t]{2}{*}{$2050 \mathrm{~s}$} & 10.7 & 11.9 & 12.7 & 12.5 & 11.5 & 9.9 & 8.3 & 6.9 & 5.5 & 6.0 & 7.1 & 8.9 \\
\hline & 10.0 & 10.8 & 11.2 & 10.8 & 10.3 & 9.1 & 5.3 & 0.8 & 0.8 & 1.1 & 4.4 & 7.8 \\
\hline \multirow[t]{2}{*}{$2090 \mathrm{~s}$} & 8.8 & 10.1 & 11.1 & 11.0 & 9.7 & 7.6 & 4.8 & 2.3 & 0.3 & 1.4 & 3.7 & 6.2 \\
\hline & 6.6 & 9.1 & 9.9 & 9.8 & 9.3 & 7.2 & 1.7 & 0 & 0 & 0 & 0.3 & 2.8 \\
\hline \multirow[t]{2}{*}{$\Delta 2050 \mathrm{~s}$} & -2.4 & -2.1 & -2.0 & -1.7 & -1.8 & -1.8 & -1.9 & -2.1 & -2.3 & -3.2 & -3.5 & -3.2 \\
\hline & -2.4 & -2.2 & -2.0 & -2.0 & -1.6 & -1.3 & -3.4 & -5.8 & -4.7 & -6.2 & -4.4 & -3.0 \\
\hline \multirow[t]{2}{*}{$\Delta 2090 \mathrm{~s}$} & -4.3 & -3.9 & -3.6 & -3.2 & -3.6 & -4.1 & -5.4 & -6.7 & -7.5 & -7.8 & -6.9 & -5.9 \\
\hline & -5.8 & -3.9 & -3.3 & -3.0 & -2.6 & -3.2 & -7.0 & -6.6 & -5.5 & -7.3 & -8.5 & -8.0 \\
\hline
\end{tabular}

clones tracked from the ERA-40 reanalysis and from highresolution satellite data, Condron et al. (2006) have shown that the failure to capture mesoscale cyclones is especially problematic in the subarctic North Atlantic. The polar low climatologies of Bracegirdle and Gray (2008), Zahn and von Storch (2008) and Zappa et al. (2014b) also show maxima in the subpolar North Atlantic, while Yanase et al. (2015) portray the corresponding climatologies over the Sea of Japan. In the present study, our coarse-resolution models are compared with the coarse-resolution ERA-I reanalysis using the same tracking algorithm, so there is general consistency in the resolution and by implication in the underestimation of cyclones. Nevertheless, the estimates of cyclones reported here from all three sources (ERA-I, NorESM, CCSM) are almost certainly low relative to the actual numbers, and our findings pertain only to systems of synoptic scale and larger.

For the historical time period, the three data sets are interpolated to a $1^{\circ} \times 1^{\circ}$ regular latitude-longitude grid for comparison. NorESM and CCSM historical means are also compared to future projections, albeit then on their respective native grids as these comparisons are rather between time periods than models. The future time periods are 2037-2063 (mid-century) and 2074-2100 (end of the century). For these two periods, both RCP4.5 and RCP8.5 are analysed (van Vuuren et al., 2011). These represent pathways with stabilization without overshooting to $4.5 \mathrm{~W} \mathrm{~m}^{-2}$ by 2100 , and a continuous increase to $8.5 \mathrm{~W} \mathrm{~m}^{-2}$ by 2100 , respectively.

\subsection{Temporal and spatial scales}

While the storm track analysis is based on 6-hourly zonal ( $u$ ) and meridional $(v)$ wind data, sea ice concentration (SIC), sea ice extent (SIE), sea level pressure (SLP) and total precipitation (hereafter referred to simply as precipitation) examined here are monthly averages. All parameters are derived from ERA-I (historical time period only), NorESM and CCSM, with the exception of historical SIE. The latter is from the National Snow and Ice Data Center (NSIDC; Fetterer et al., 2002). SIE is the area of all grid cells with SIC $>15 \%$.

Table 1 shows the monthly mean SIE averaged over a historical and two future scenario time periods in NSIDC (historical time period only), NorESM and CCSM. The seasonal cycle of climatological monthly SIE for the previous decade is captured by the two models, although both models show weaker seasonal cycles of ice retreat compared to the observational data from NSIDC. Nevertheless, Langehaug et al. (2013) found the relative trends in NorESM to be close to those observed. The projected SIE reduction is greatest in the autumn and early winter, especially in terms of the percentage reduction from the historical values. Even the areal reductions are largest during this portion of the year (Table 1). Moreover, the observed ice loss during recent decades (1979-present) is also greatest during the autumn (Stroeve et al., 2012; Rogers et al., 2013). In view of this seasonality, we focus our analysis on the extended autumn season September through December (SOND).

Figure 1 presents the representation of SIC over the historical time period in the two models, as well as projected changes in SIC over future scenarios and time periods relative to the historical time period. Both models simulate a seasonally ice-free ( $\mathrm{SIE}<1$ million $\mathrm{km}^{2}$ ) Arctic Ocean during the second half of the 21 st century, with a slightly more rapid sea ice retreat in CCSM than NorESM. This trend motivates the region of focus, where retreating sea ice is expected to modify distribution and intensity of storminess parameters.

\subsection{Methods}

The storm track analysis is based on the TRACK algorithm described by Hodges (1994, 1995, 1999). It uses 6-hourly $850 \mathrm{hPa}$ relative vorticity $(\zeta)$ to identify and track cyclones, here calculated from the $u$ and $v$ fields. Rather than SLP, $\zeta$ is 
(a) NorESM 1979-2005

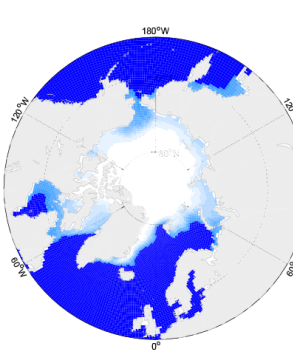

(f) $C C S M$ 1979-2005 (b) NorESM

RCP4.5 2037-20631979-2005

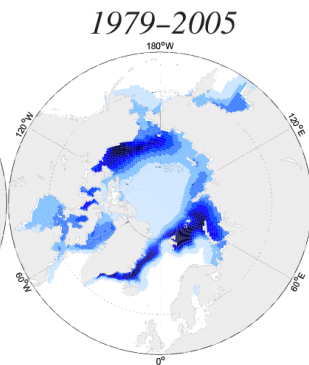

(g) CCSM RCP4.5 2037-2063RCP4.5 $2037-2063$ (c) NorESM RCP8.5 2037-20631979-2005 (d) NorESM

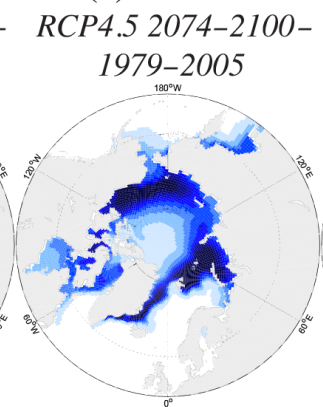

(i) $C C S M$

(h) $C C S M$

RCP8.5 2037-2063

RCP4.5 2074-2100-

1979-2005

1979-2005
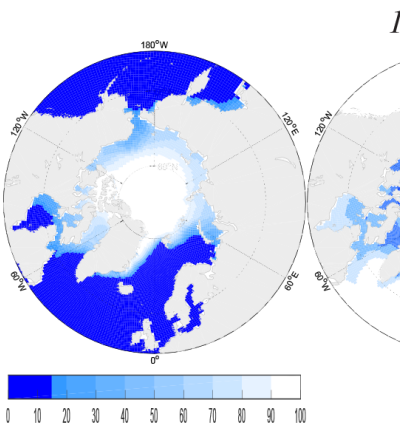

(e) NorESM

RCP8.5 2074-21001979-2005

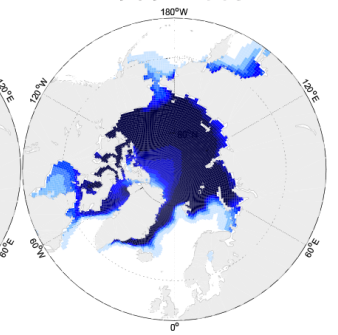

(j) $C C S M$

RCP8.5 2074-21001979-2005

Figure 1. Sea ice concentration (a, f) averages for SOND 1979-2005 and (b-e, $\mathbf{g}-\mathbf{j})$ changes in average over various time periods and scenarios compared to 1979-2005 in NorESM (upper row) and CCSM (lower row). The time periods and scenarios are (b, g) RCP4.5 20372063 - 1979-2005, (c, h) RCP8.5 2037-2063 - 1979-2005, (d, i) RCP4.5 2074-2100 - 1979-2005 and (e, j) RCP8.5 2074-2100 - 19792005 .

used for tracking due to the focus on storminess. $\zeta$ contains more information on the wind field and the high-frequency range of the synoptic scale, whereas SLP is linked to the mass field and represents the low-frequency scale better (Hodges et al., 2003). This results in generally more cyclones identified using vorticity tracking compared to using SLP (Hodges et al., 2011). Not including the TRACK algorithm, Neu et al. (2013) found the number of storms identified by methods based on vorticity to be in the middle range of those obtained using different tracking algorithms. Rather, number of cyclones detected appears to decrease with decreasing resolution of the input data (Pinto et al., 2005).

The $\zeta$ field at moderate to high resolution can nevertheless be very noisy. Hence, to allow the same spatial synoptic scales to be identified in the three data sets, the analysis is performed at a spectral resolution of T42 on a Gaussian grid. Additionally, planetary scales with wave numbers below 5 and above 42 are removed to focus on the synoptic variability. This follows from the data set resolutions and allows some, but not all, polar lows to be resolved (Zappa et al., 2014b). Finally, criteria regarding their displacement distance (minimum $1000 \mathrm{~km}$ ) and lifetime (minimum 2 days) are set. Only cyclones (not anticyclones) are considered.

For this study, two Eulerian statistical fields are of interest: the track density (a relative measure of how many cy- clones pass through a region) and the mean intensity (a measure of the strength of the cyclones). These are computed by the spherical kernel estimators described in Hodges (1996). While the mean intensity unit corresponds to relative vorticity $\left(10^{-5} \mathrm{~s}^{-1}\right)$, the track density is given in units of number density per month per unit area, where the unit area is equivalent to a $5^{\circ}$ spherical cap $\left(\sim 10^{6} \mathrm{~km}^{2}\right)$. Although changes of track density also could result from more (less) tightly confined cyclones, they are more likely due to an increase (decrease) in the number of cyclones. Hence, in the following, we refer to changes in the density fields as more or fewer cyclones.

Significance testing of the SIC, SLP and precipitation fields follow the Student's two-sided $t$ test with a $5 \%$ significance criterion. For the storm track characteristics, $p$ values (the probability that a more extreme value is possible by chance) are computed using a permutation Monte Carlo approach (sampling without replacement; Hodges, 2008). Correspondingly, grid points with $p<0.05$ are denoted as significant in storm track figures.

\section{Results and discussion}

In the following, parameters representing storminess are presented. Section 3.1 compares the representation of each sce- 
(a) NorESM 1979-2005

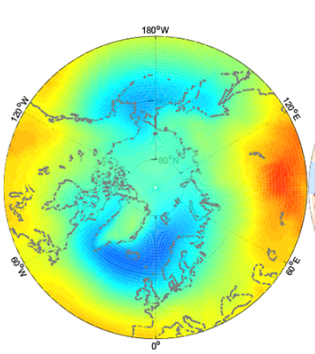

(f) $C C S M$ 1979-2005

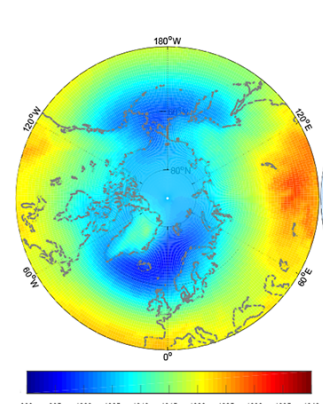

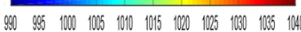

(b) NorESM

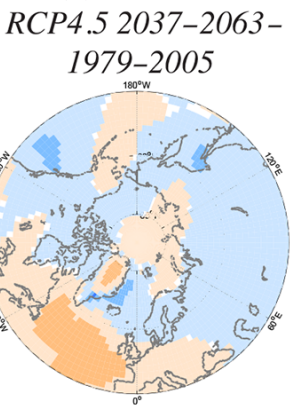

(g) $C C S M$

RCP4.5 2037-20631979-2005 (c) NorESM

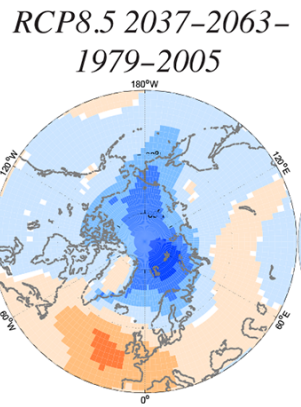

(h) $C C S M$

RCP8.5 2037-2063- (d) NorESM

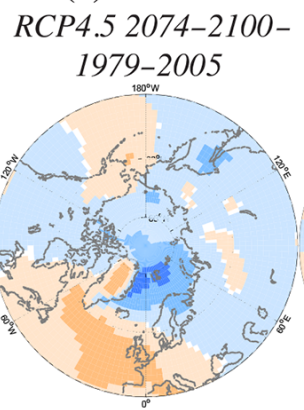

(i) $C C S M$

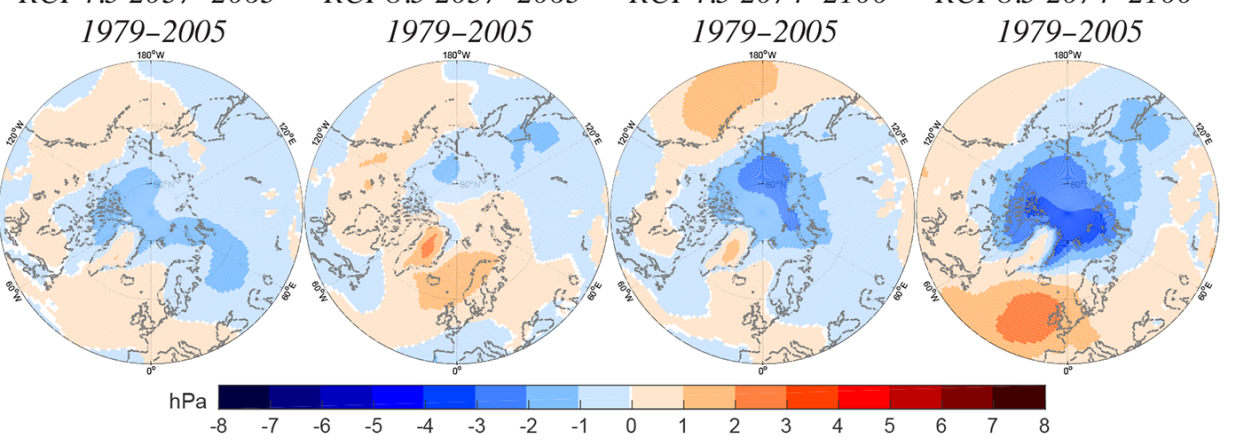

Figure 2. Sea level pressure (a, f) averages for SOND 1979-2005 and (b-e, $\mathbf{g}-\mathbf{j}$ ) changes in average over various time periods and scenarios compared to 1979-2005 in NorESM (upper row) and CCSM (lower row). The time periods and scenarios are (b, g) RCP4.5 2037-2063 1979-2005, (c, h) RCP8.5 2037-2063 - 1979-2005, (d, i) RCP4.5 2074-2100 - 1979-2005 and (e, j) RCP8.5 2074-2100 - 1979-2005.

nario and time period in each of the models, explaining the choice of one scenario and time period for the future projections. NorESM and CCSM are compared to ERA-I over the historical time period in Sect. 3.2. Section 3.3 outlines the expected changes of the storminess parameters towards the end of the century, as projected by NorESM and CCSM.

\subsection{Scenario and time period comparisons}

Figures 2 to 5 picture the representation of the storminess parameters SLP, track density, mean intensity and precipitation in the two models. For each figure, the first column represents the historical time period, with increasing RCP value and time in the succeeding columns.

Projected changes in sea ice, SLP, track density, mean intensity and precipitation suggest a near-linear scaling with strength of scenario (RCP4.5 and RCP8.5) and time (19792005 to 2037-2063 and 2074-2100) in the two models (Table 1 and Figs. 1 to 5). Hence, we consider the 2037-2063 time period to be an intermediate state between the 19792005 and 2074-2100 periods, and the RCP4.5 scenario to be midway to the RCP8.5 scenario. This explains the choice in Sect. 3.3, where the 2074-2100 time period following the RCP8.5 scenario is the only scenario to be compared to the historical time period.
While the scaling appear more distinct for sea ice, SLP and precipitation, Figs. 3 and 4 show signs of similar behaviour for storm frequency and intensity. This is partly in contrast to Catto et al. (2011). Using the High Resolution Global Environment Model (HiGEM), they found northeastward shift of the North Atlantic storm track for the idealized, doubled $\mathrm{CO}_{2}$ experiment only and not for quadrupled $\mathrm{CO}_{2}$. The CMIP5 model RCP4.5 and RCP8.5 scenarios here are not directly comparable as they represent weaker increases in $\mathrm{CO}_{2}$ (about $1.5 \times \mathrm{CO}_{2}$ and $2.5 \times \mathrm{CO}_{2}$ in 2070-2100 compared to 19792005). Nevertheless, in our results, the northeastward shift gets stronger with scenario and time in NorESM (Figs. 3a to e and 4a to e). In CCSM, the North Atlantic storm track generally weakens with scenario and time (Figs. $3 \mathrm{f}$ to $\mathrm{j}$ and 4f to $j$ ). Overall, signals strengthen with scenario and time in both models. These results extend those of Zappa et al. (2013b), who found mean response generally larger, but with larger inter-model spread, for RCP8.5 than for RCP4.5 in 19 CMIP5 models (not including CCSM).

Table 2 presents the main results of this study. Representing circumglobal averages spanning large areas, the averages for mid- and high latitudes might cancel out variations within each region. However, the maps presented in Sect. 3.2 and 3.3 will disclose these features. The values in Table 2 are discussed in more detail in these sections. 
(a) NorESM 1979-2005

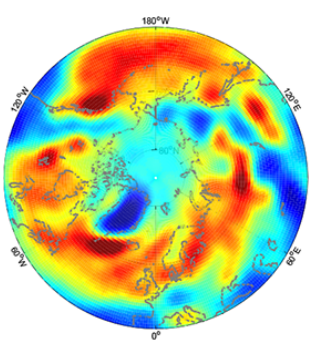

(f) $C C S M$

1979-2005

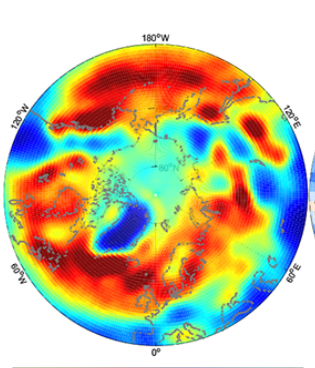

$1 \begin{array}{llllllllll}2 & 3 & 4 & 5 & 6 & 7 & 8 & 9 & 10 & 11121314\end{array}$ (b) NorESM

RCP4.5 2037-2063$1979-2005$

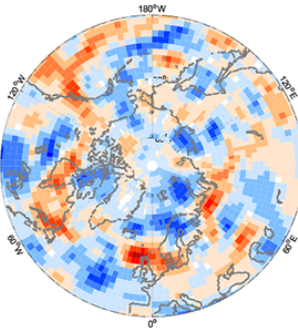

(g) $C C S M$

RCP4.5 2037-20631979-2005

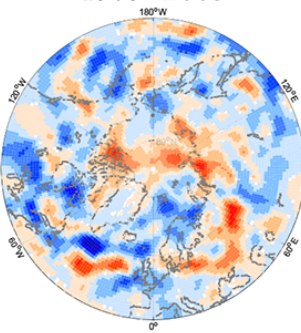

No. dens (month) $)^{-1}\left(10^{6} \mathrm{~km}^{2}\right.$ (c) NorESM

RCP8.5 2037-20631979-2005

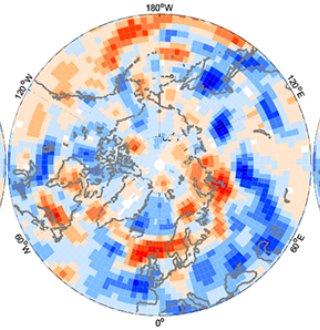

(h) $C C S M$

RCP8.5 2037-20631979-2005 (d) NorESM

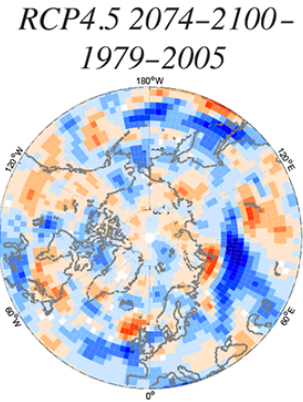

(i) $C C S M$

RCP4.5 2074-2100- (e) NorESM

RCP8.5 2074-2100

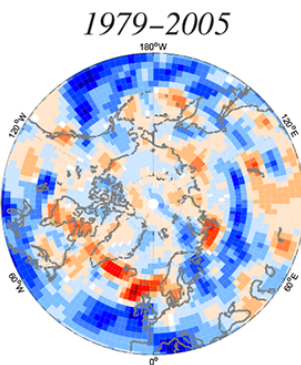

(j) $C C S M$

RCP8.5 2074-2100 1979-2005

Figure 3. Track density (a,f) averages for SOND 1979-2005 and (b-e, g-j) changes in average over various time periods and scenarios compared to 1979-2005 in NorESM (upper row) and CCSM (lower row). The time periods and scenarios are (b, g) RCP4.5 2037-2063 - 19792005, (c, h) RCP8.5 2037-2063 - 1979-2005, (d, i) RCP4.5 2074-2100 - 1979-2005 and (e, j) RCP8.5 2074-2100 - 1979-2005.

(a) NorESM 1979-2005

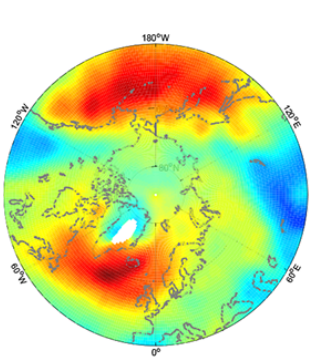

(f) $C C S M$ 1979-2005

(b) NorESM

(c) NorESM

(d) NorESM

(e) NorESM RCP4.5 2037-2063 - RCP8.5 2037-2063 - RCP4.5 2074-2100 - RCP8.5 2074-2100 -

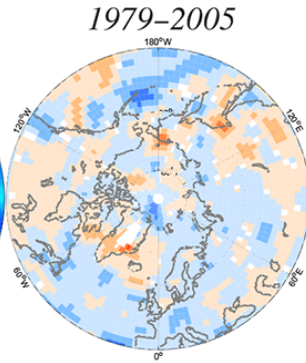

(g) $C C S M$

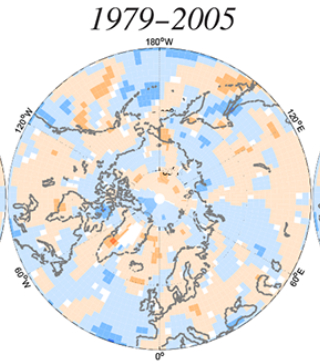

(h) $C C S M$

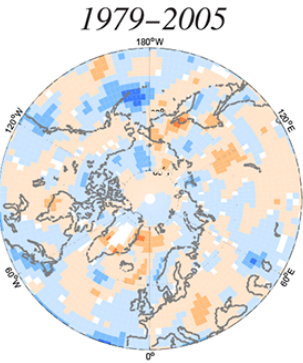

(i) $C C S M$

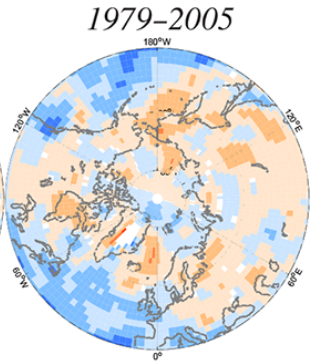

(j) $C C S M$ RCP4.5 2037-2063 - RCP8.5 2037-2063- RCP4.5 2074-2100 - RCP8.5 2074-2100 1979-2005
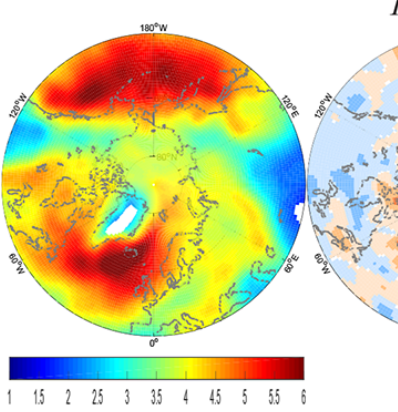

1979-2005
RCP4.5 $2074-2100$
$1979-2005$ 1979-2005

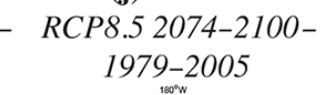


(a) NorESM

1979-2005

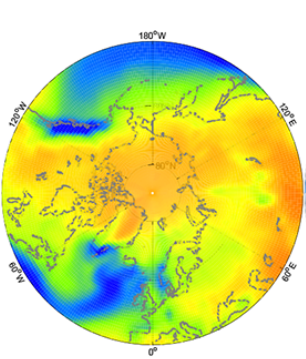

(f) $C C S M$

1979-2005

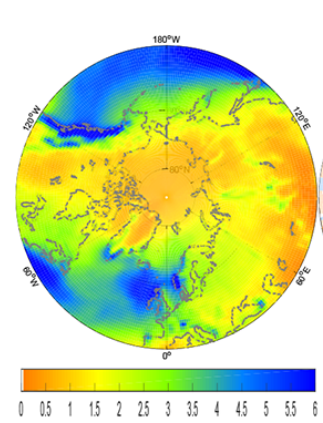

(b) NorESM

RCP4.5 2037-20631979-2005

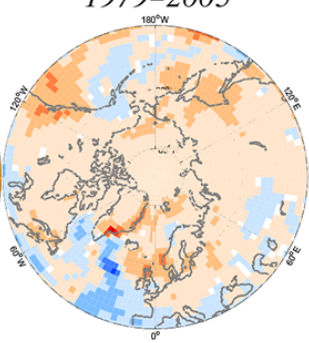

(g) $C C S M$

RCP4.5 2037-2063 1979-2005 (c) NorESM

RCP8.5 2037-2063- (d) NorESM

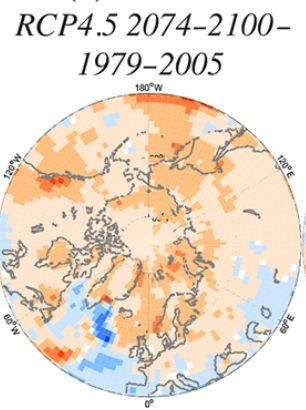

(i) $C C S M$

(h) $C C S M$

RCP8.5 2037-2063-

1979-2005

RCP4.5 2074-2100-

1979-2005
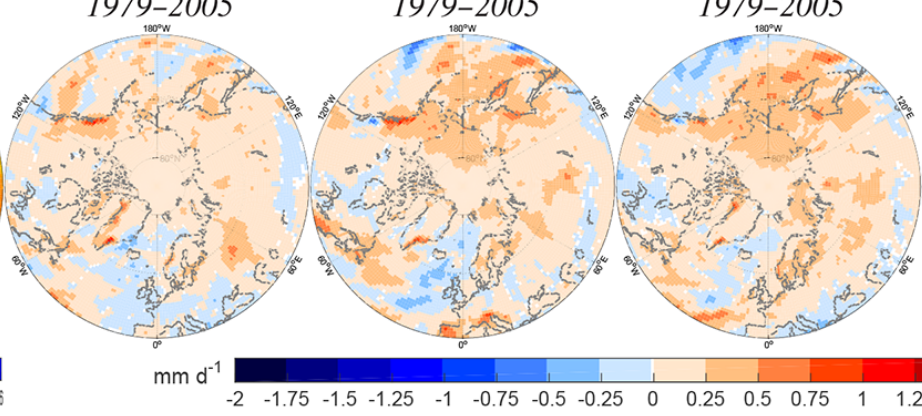

(e) NorESM

RCP8.5 2074-21001979-2005

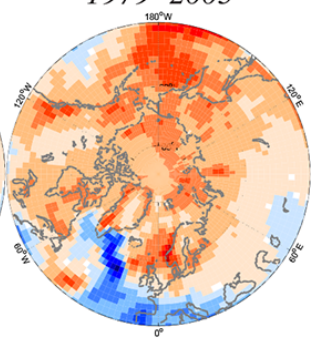

(j) $C C S M$

RCP8.5 2074-2100-

1979-2005

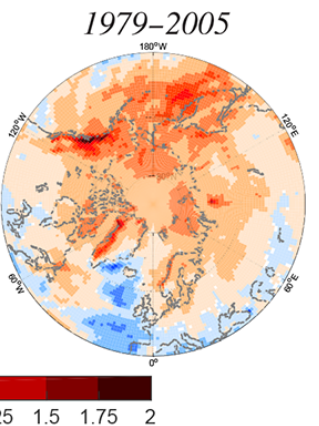

Figure 5. Precipitation (a,f) averages for SOND 1979-2005 and (b-e, g-j) changes in average over various time periods and scenarios compared to 1979-2005 in NorESM (upper row) and CCSM (lower row). The time periods and scenarios are (b, g) RCP4.5 2037-2063 - 19792005, (c, h) RCP8.5 2037-2063 - 1979-2005, (d, i) RCP4.5 2074-2100 - 1979-2005 and (e, j) RCP8.5 2074-2100 - 1979-2005.

\subsection{Historical time period}

\subsubsection{Sea level pressure}

SLP variations are indirect measures of large-scale storminess. Pressure gradients in space and pressure changes for a particular point in time both provide indications of storm activity. The activity generally increases with decreasing SLP as cyclones lower the SLP of a region as they track through (Trenberth et al., 2007, and references therein).

Under the assumption that ERA-I represents the actual conditions (Fig. 6a), NorESM and CCSM reproduce the main SLP pattern (Fig. 2a and f), but both also show distinct biases (Fig. $6 \mathrm{~b}$ and c). In midlatitudes (here defined $40-65^{\circ} \mathrm{N}$ ), differences are small, with most of the variations due to the representation of the Siberian High (Table 2), which is slightly strengthened and shifted equatorwards in the two models (Fig. 6). This bias is stronger in NorESM, which represents the Siberian High with SLP up to $1031 \mathrm{hPa}$ compared to the maximum of $1027 \mathrm{hPa}$ in ERA-I.

Contrary to the equatorward-shifted Siberian High, the local minima of the Aleutian and Icelandic lows are shifted polewards in the two models, as represented by the positive (negative) SLP bias south (north) of the pressure system centres in Fig. 6. This coincides with the marked negative bias in high latitudes (here defined 65-90 $\mathrm{N}$ ) in both models, where
NorESM and CCSM depict 2 and $6 \mathrm{hPa}$, respectively, lower SLP than ERA-I (Table 2 and Fig. $6 b$ and c).

The substantial SLP bias in CCSM was also noted by DeWeaver and Bitz (2006), who compared the two resolutions T42 and T85 of CCSM3 (CCSM version 3) to the National Centers for Environmental Prediction (NCEP)/NCAR reanalysis. CCSM3 simulated pressures that were too low for the Aleutian and Icelandic Lows, but with the largest SLP anomalies located over the Beaufort Sea. They found the bias to be more pronounced in the higher resolution, and ascribed this deficiency to the model's inability to simulate the Beaufort High in autumn, winter and spring. de Boer et al. (2012) showed that this same bias persists in CCSM4.

\subsubsection{Track density}

Figures $3 \mathrm{a}$, $\mathrm{f}$ and $7 \mathrm{a}$ show the distribution in cyclone frequency in the three data sets. The two main storm tracks of the North Atlantic and the North Pacific oceans are apparent, and likewise the local maxima over Canada and northern Eurasia.

Compared to ERA-I, both models depict poleward-shifted storm tracks over the North Pacific Ocean, Canadian Arctic and the Nordic Seas (Fig. 7b and c). On the contrary, the eastern branch of the North Atlantic storm track is broader and extends farther south in the models. These features of- 

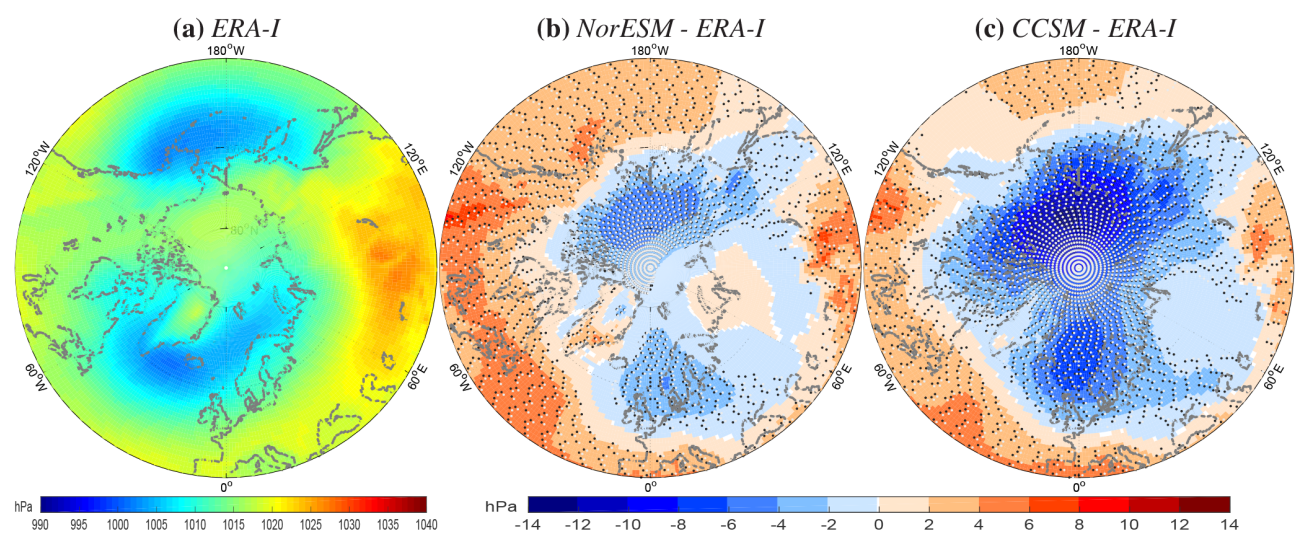

Figure 6. Sea level pressure average for SOND 1979-2005 in (a) ERA-I and bias of (b) NorESM and (c) CCSM compared to ERA-I. Alternating black and white dots in panels (b) and (c) mark regions of significant bias at a $95 \%$ confidence level.

Table 2. Time period mean sea level pressure (SLP), track density (tden), mean intensity (mint) and precipitation ( $P$ ) SOND averages for 1979-2005 (1979-2005) and changes for 2074-2100 relative to 1979-2005 following the RCP8.5 scenario ( $\Delta 2074-2100)$ in ERA-I, NorESM and CCSM. First number within each column denotes average over midlatitudes $\left(40-65^{\circ} \mathrm{N}\right)$; second number within each column denotes average over high latitudes $\left(65-90^{\circ} \mathrm{N}\right)$. For 1979-2005, units are $\mathrm{hPa}$, no. dens (month) ${ }^{-1}\left(10^{6} \mathrm{~km}^{2}\right)^{-1}, 10^{-5} \mathrm{~s}^{-1}$ and $\mathrm{mm} \mathrm{d}^{-1}$ for SLP, tden, mint and $P$, respectively. For $\Delta 2074-2100$, unit is $\%$.

\begin{tabular}{llrrrrrrrr}
\hline Data set & Time period & \multicolumn{2}{c}{ SLP } & \multicolumn{2}{c}{ tden } & \multicolumn{2}{c}{ mint } & \multicolumn{2}{r}{$P$} \\
\hline ERA-I & $1979-2005$ & 1015 & 1012 & 9.0 & 7.0 & 4.2 & 3.7 & 2.5 & 1.2 \\
NorESM & $1979-2005$ & 1016 & 1010 & 8.9 & 6.8 & 4.0 & 3.8 & 2.5 & 1.2 \\
& $\Delta 2074-2100$ & 0.02 & -0.24 & -3.9 & 0.3 & -0.2 & 0.9 & 10.7 & 38.2 \\
CCSM & $1979-2005$ & 1015 & 1006 & 9.5 & 7.7 & 4.2 & 3.9 & 2.8 & 1.4 \\
& $\Delta 2074-2100$ & 0.02 & -0.18 & -6.5 & -0.8 & -1.7 & 2.9 & 8.0 & 31.8 \\
\hline
\end{tabular}

fer an explanation for the poleward-shifted and wider low SLP bands in Fig. 6. For the North Atlantic Ocean overall, cyclones in NorESM and CCSM are slightly too zonal compared to ERA-I, consistent with the winter pattern found in CMIP5 models by Zappa et al. (2013a). This leaves fewer cyclones tracking through the Greenland Sea - the region where most Arctic cyclones track (Sorteberg and Walsh, 2008). It is worth mentioning that the zonal North Atlantic storm track bias is stronger in CCSM than in NorESM (Figs. 3a, $f$ and $7 \mathrm{~b}$ and $\mathrm{c}$ ). This coincides with a sea ice pattern of higher (lower) SIC in the Labrador Sea (Greenland and Barents seas) in CCSM compared to NorESM (Fig. If compared to Fig. 1a). This sea ice anomaly pattern was also found to be associated with weaker and more zonal North Atlantic storm track in CCSM3 during winter (Magnusdottir et al., 2004).

In CCSM, the number of cyclones within the domain of $40-90^{\circ} \mathrm{N}$ is $7 \%$ higher than in ERA-I, mainly due to the positive bias in high latitudes (Table 2 and Fig. 7c). On the contrary, there are $2 \%$ fewer cyclones in NorESM than found in ERA-I (Table 2 and Fig. 7b). For NorESM, this anomaly stems from its resolution, which is about 4 times as coarse as in the reanalysis. This leaves fewer cyclones resolved (Pinto et al., 2005; Hodges et al., 2011).
The cyclone frequency bias in CCSM offers an additional explanation to the large-scale background SLP biases across the main storm tracks discussed in Sect. 3.2.1. As more cyclones are resolved in CCSM compared to ERA-I (Table 2), a particular grid point in the main storm track undergoes lower SLP for more time steps, understandably dependent on the cyclone strength. For regions of the main storm tracks, this can lower the SLP temporal mean. This is indicated by the anomalous low SLPs over the poleward-shifted North Atlantic and North Pacific storm tracks (Figs. 6c and 7c).

Moreover, most of the discrepancy relative to ERA-I stems from the high latitudes south of the Arctic Ocean, with $14 \%$ more cyclones in CCSM over the band $55-65^{\circ} \mathrm{N}$ (Fig. 7c). This points to a closer similarity of CCSM to the Arctic System Reanalysis (ASR) over ERA-I, as found by Tilinina et al. (2014). They detected $28-40 \%$ more cyclones over high-latitude continental areas in summer and winter in the ASR compared to ERA-I and other global modern era reanalyses, ascribing the anomaly mostly to moderately deep and shallow cyclones (cyclones with central pressure higher than $980 \mathrm{hPa}$ ). 

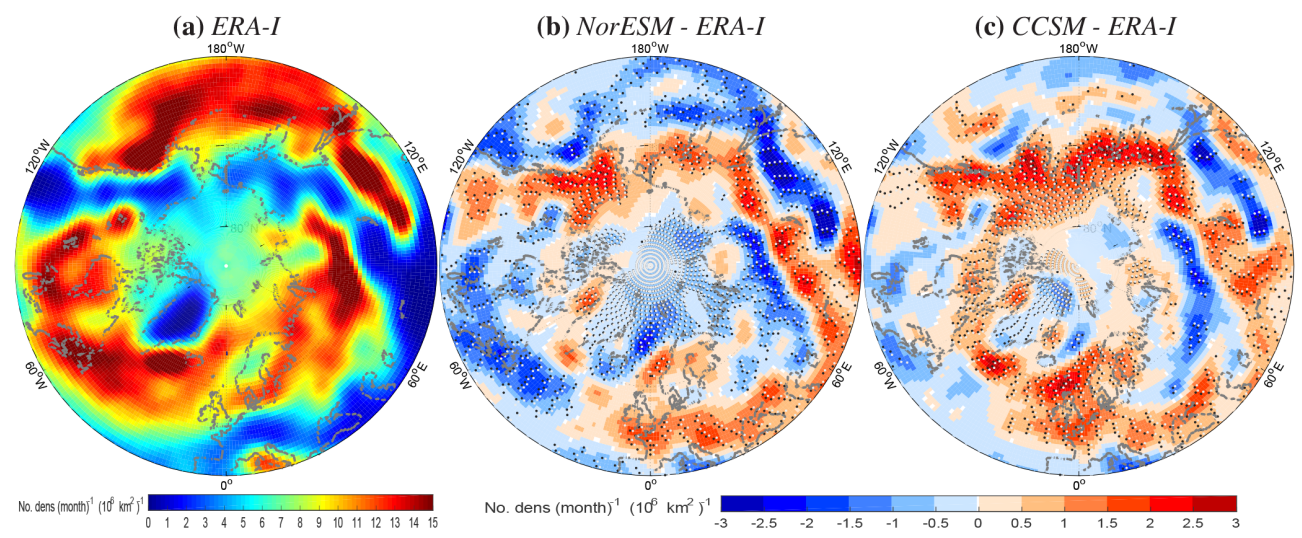

Figure 7. Track density average for SOND 1979-2005 in (a) ERA-I and bias of (b) NorESM and (c) CCSM compared to ERA-I. Alternating black and white dots in panels (b) and (c) mark regions where $p<0.05$ based on 2000 samples.

\subsubsection{Mean intensity}

The average strength of cyclones per unit area is presented in Figs. 4a, $\mathrm{f}$ and 8a. This is measured as mean intensity, indirectly linked to spatial changes in wind fields through the horizontal component of relative vorticity. Since regions of numerous cyclones are likely also to include more intense cyclones than other regions, the mean intensity pattern generally follows the track density pattern in Figs. 3a, $\mathrm{f}$ and $7 \mathrm{a}$. Additionally, cyclones are stronger over ocean than land.

Corresponding to the general poleward shift of the SLP minima and track density maxima along the two main storm tracks relative to ERA-I (Figs. 6 and 7), NorESM and CCSM have too low mean intensities over the North Atlantic and North Pacific oceans (Fig. 8b and c). Conversely, as for track density, positive biases are found over large swaths of Eurasia and western North America, indicating lower contrasts between regions of high and low cyclonic activity in the models compared to ERA-I (Figs. 7b, c, and 8b, c).

Model biases are generally more coherent (spatially homogeneous) for mean intensity than track density (Fig. 8b and c compared to Fig. $7 b$ and c), where stronger (weaker) cyclones correspond to lower (higher) SLP (Table 2). However, this relationship does not hold for sea ice-covered areas (Fig. $8 \mathrm{~b}$ and c compared to Fig. $6 \mathrm{~b}$ and c).

In addition to the displacement of the density features in the two models compared to the reanalysis, cyclones are generally weaker in cyclone-dense regions and stronger in cyclone-light regions (Fig. 8). As with track density (Fig. 7), the values in NorESM are generally lower.

Our results add to the CMIP5 model underestimation of cyclone intensities in the North Atlantic Ocean in winter and summer compared to ERA-I found by Zappa et al. (2013a). They attributed this bias to either an incorrect representation of dynamical processes on the spatiotemporal scales of cyclones (e.g. baroclinic conversion, diabatic heating, dissipation) or to biases in the large-scale processes (e.g. flow- orography interaction, tropical convection, radiative forcing) that determine the environment in which the cyclones grow. Here, Fig. 8 shows that cyclones are generally weaker in the two CMIP5 models NorESM and CCSM than ERA-I also in the extended autumn season.

\subsubsection{Precipitation}

In terms of broad-scale pattern, precipitation is positively correlated with storminess, although one cannot say that precipitation is a real measure of storminess. Hawcroft et al. (2012) and Catto et al. (2012) showed the proportion of precipitation associated with extratropical cyclones and fronts, respectively. Only through this type of linkage can a causal relationship be established. In this study, because precipitation per se is not our main focus, we merely point to consistencies between our results and general characteristics of precipitation vis-à-vis its drivers. For example, cyclone-dense regions are generally characterized by high frontal precipitation, with precipitation reaching especially high levels where cyclones track into mountainous land so that precipitation is orographically enhanced.

Figures 5a, $\mathrm{f}$ and $9 \mathrm{a}$ show the average pattern of precipitation for NH midlatitudes and high latitudes over the historical time period. While climate models generally distinguish convective and non-convective precipitation, their archives do not distinguish frontal and orographic precipitation - two of the primary types of non-convective precipitation. Nevertheless, one can infer that heavy precipitation events in nonmountainous areas have a general association with frontal activity (Kunkel et al., 2012), while precipitation maxima in mountainous areas have a substantial orographic component. Subject to these assumptions, some inferences can be made about the key features that stand out in Fig. 9.

First, frontal precipitation accounts for a large fraction of the precipitation, as seen from the close similarity between the precipitation (Figs. 5a, f and 9a) and cyclone track density fields (Figs. 3a, f and 7a). Second, orographic precipi- 

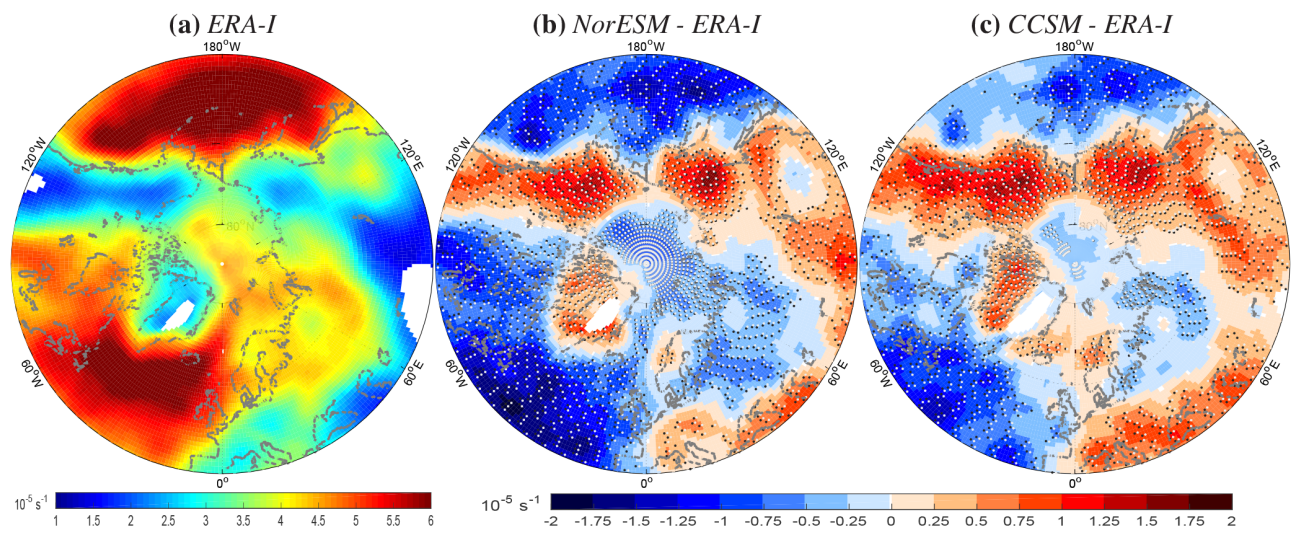

Figure 8. Mean intensity average for SOND 1979-2005 in (a) ERA-I and bias of (b) NorESM and (c) CCSM compared to ERA-I. Regions with track density below 0.5 no. density (month) ${ }^{-1}\left(10^{6} \mathrm{~km}^{2}\right)^{-1}$ are shaded white. Alternating black and white dots in panel (b) and (c) mark regions where $p<0.05$ based on 2000 samples.
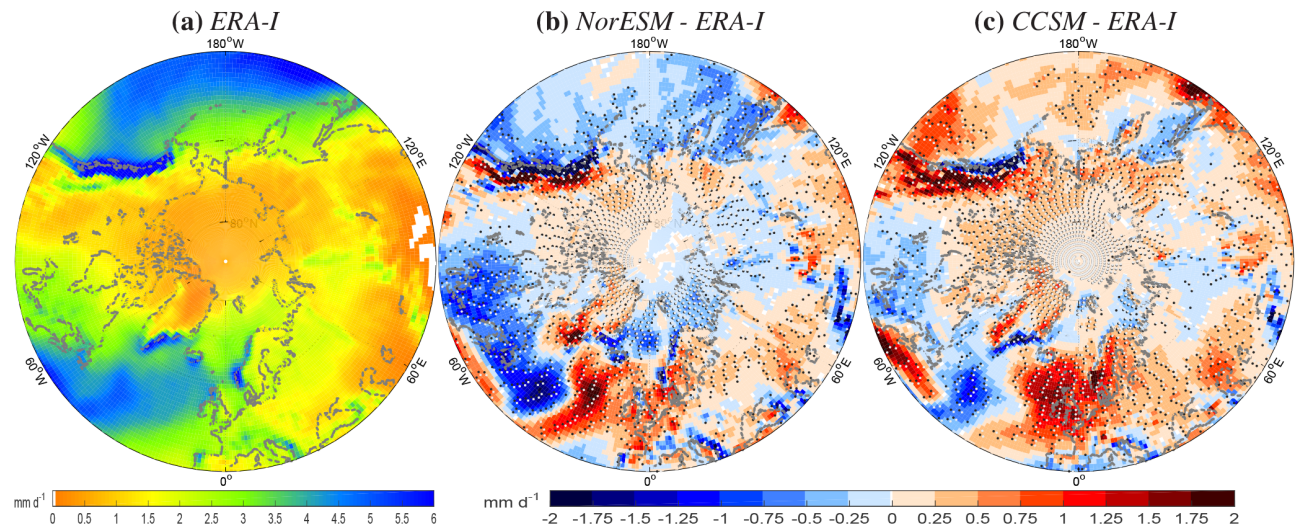

Figure 9. Precipitation average for SOND 1979-2005 in (a) ERA-I and bias of (b) NorESM and (c) CCSM compared to ERA-I. Alternating black and white dots in panels (b) and (c) mark regions of significant bias at a $95 \%$ confidence level.

tation is assumed to be the second most important component to the precipitation. This can be seen from the maxima where the main storm tracks reach land (the west coasts of North America, Scotland and Norway, and the south coasts of Greenland and Iceland in Figs. 5a, f and 9a). Moreover, local maxima in connection with the Rocky and Cantabrian mountains, the French and Dinaric alps, as well as Caucasus and the mountains of Japan point to the role of the water bodies to the west of these mountains (Figs. 5a, f and 9a). As the westerly wind crosses these waters, the air gains moisture that later result in orographic precipitation on the windward side of the mountains as the air is forced upwards.

Frontal precipitation is represented reasonably well in NorESM and CCSM (Fig. 5a and f compared to Fig. 9a, and Figs. 5a, f and 9a compared to Figs. 3a, f and 7a). However, in the North Atlantic Ocean, both models give the precipitation field an orientation that is too zonal in the western half and too meridional in the eastern half. As a consequence, considerably more precipitation falls in the northeastern corner of the North Atlantic Ocean in NorESM and CCSM compared to ERA-I (Fig. 9b and c).

The orographic precipitation maxima at storm track landfall in the two models are shifted inland compared to ERA-I (Fig. $9 \mathrm{~b}$ and c). This is likely a result of the resolution difference, in which elevation gradients are smoothed (i.e. weakened) over larger grid boxes. With a prevailing westerly wind in the domain, the air "feels" the mountains later (i.e. farther east) in NorESM and CCSM than in ERA-I. Moreover, the coarse resolution of NorESM restricts the ability to represent orographic precipitation, so the orographic maxima in NorESM are too weak (Fig. 9b).

For this reason, and due to the fewer cyclones resolved (Sect. 3.2.2), we would expect to see less precipitation in NorESM than ERA-I. However, the difference over the domain is only a $1 \%$ reduction (Table 2). This indicates that cyclone frequency may have a greater impact on precipitation than cyclone strength, as the corresponding negative biases over the domain for track density and mean intensity are 2 and $5 \%$, respectively. CCSM, with both more and stronger 
Table 3. Changes of track density (tden; first row), mean intensity (mint; second row) and precipitation ( $P$; third row) over September and December for 2074-2100 relative to 1979-2005 following the RCP8.5 scenario in NorESM and CCSM in four North Atlantic and North Pacific storm track regions. The regions are western North America (WNA; 50-58 ${ }^{\circ} \mathrm{N}, 125-137^{\circ} \mathrm{W}$ and $58-62^{\circ} \mathrm{N}, 136-155^{\circ} \mathrm{W}$ ), Bering and western Alaska (BWA; 55-72 ${ }^{\circ} \mathrm{N}, 155-180^{\circ} \mathrm{W}$ ), northwestern Europe (NWE; 55-65 $\left.{ }^{\circ} \mathrm{N}, 15^{\circ} \mathrm{W}-15^{\circ} \mathrm{E}\right)$ and northeastern Europe $(\mathrm{NEE}$; $65-$ $75^{\circ} \mathrm{N}, 10^{\circ} \mathrm{W}-50^{\circ} \mathrm{E}$ ). First number within each column denotes change in September; second number within each column denotes change in December. Unit is \%.

\begin{tabular}{|c|c|c|c|c|c|c|c|c|c|}
\hline \multirow{2}{*}{$\begin{array}{l}\text { Parameter } \\
\text { tden }\end{array}$} & \multirow{2}{*}{$\begin{array}{l}\text { Data set } \\
\text { NorESM }\end{array}$} & \multicolumn{2}{|c|}{ WNA } & \multicolumn{2}{|c|}{ BWA } & \multicolumn{2}{|c|}{ NWE } & \multicolumn{2}{|c|}{ NEE } \\
\hline & & -20.1 & 18.2 & 11.3 & -13.4 & 12.8 & 10.2 & -6.5 & -0.8 \\
\hline & CCSM & -8.0 & -12.8 & -8.1 & 15.5 & -21.7 & 1.2 & -1.2 & -11.6 \\
\hline \multirow[t]{2}{*}{$\operatorname{mint}$} & NorESM & -6.2 & 0 & -1.4 & 3.2 & -5.9 & 4.2 & -0.1 & 1.5 \\
\hline & CCSM & -5.2 & -0.5 & 2.0 & 8.3 & -8.9 & 1.3 & 0.9 & -3.6 \\
\hline \multirow[t]{2}{*}{$P$} & NorESM & -4.1 & 15.5 & 23.8 & 21.5 & 5.7 & 19.7 & 11.7 & 21.1 \\
\hline & CCSM & 5.8 & 10.1 & 18.0 & 44.4 & -12.0 & 8.7 & 13.0 & 5.3 \\
\hline
\end{tabular}

cyclones, has $10 \%$ more precipitation over the domain than does ERA-I (Table 2).

The discussed connection between total precipitation and cyclone frequency and strength is based on an assumption that frontal precipitation is well captured in models. However, Stephens et al. (2010) found that climate models generally overestimate the frequency and underestimate the intensity of precipitation, a conclusion Catto et al. (2015) found valid also for frontal precipitation. These compensating errors were discussed in more detail by Catto et al. (2013, 2015), who found them largely to be driven by the nonfrontal precipitation regimes. These findings are consistent with the biases in NorESM and CCSM.

\subsection{Future scenario changes}

The following sections outline the projected changes in the four storminess parameters described in Sect. 3.1 and 3.2 over 2074-2100 relative to 1979-2005 following the RCP8.5 scenario in NorESM and CCSM. Because storm tracks, frequencies and intensities change substantially from September to December, 4-month means can obscure the key features of individual calendar months. Accordingly, we present time period averages for the boundary months September and December in Table 3 and Figs. 10 to 13 rather than the 4month means SOND as in Table 2 and Figs. 1 to 9.

In addition to the circumglobal averages over high and midlatitudes in Table 2, projected changes in track density, mean intensity and precipitation are evaluated for four chosen regions. The regionally averaged parameters are summarized in Table 3 and discussed in Sect. 3.3.2, 3.3.3 and 3.3.4. The regions, pictured in Fig. 11a, were chosen to enable the assessment of a potential shift in the two main historical storm tracks: the North Pacific and North Atlantic storm tracks. The western North America (WNA) and northwestern Europe (NWE) represent the landfall of the main storm tracks in the historical time period, while their northerly neighbouring regions Bering and western Alaska (BWA) and northeastern Europe (NEE) constitute the stormier regions

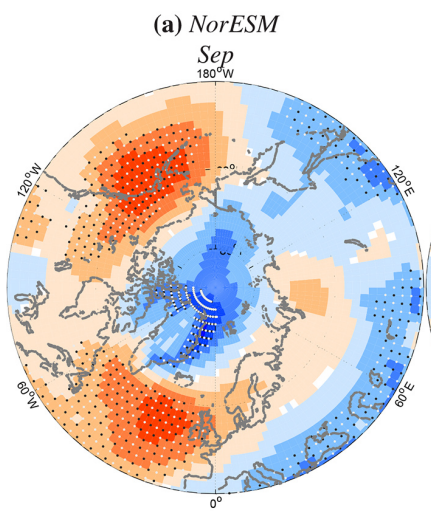

(c) NorESM

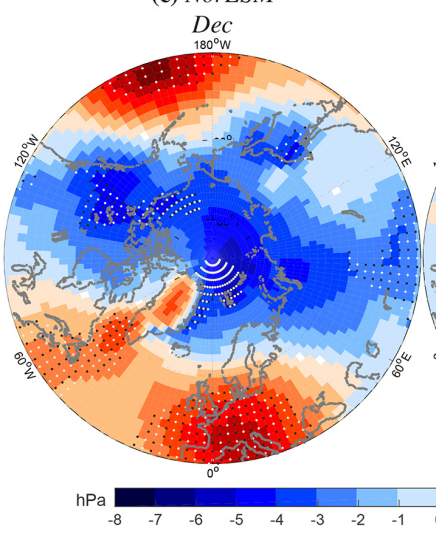

Figure 10. Changes in sea level pressure averages for September (upper row) and December (lower row) 2074-2100 compared to 1979-2005 following the RCP8.5 scenario in (a, c) NorESM and (b, d) CCSM. Alternating black and white dots mark regions of significant change at a $95 \%$ confidence level.

that could result from poleward-shifted storm tracks (see Table 3 for latitudinal and longitudinal boundaries). The four regions have very similar areas and are thus intercomparable. 


\subsubsection{Sea level pressure}

Compared to the 1979-2005 historical time period, both models show a significant reduction of $2 \mathrm{hPa}$ in the SLP field over high latitudes by the end of the century (2074-2100; Table 2 and Fig. 10). We attribute this, at least in part, to the sea ice retreat (Table 1), where most significant reductions occur in regions of sea ice retreat over the century (Fig. 10 and green lines in Fig. 12). With a later refreezing, the autumn air temperatures - although warmer than today (Overland et al., 2013) - create a substantial temperature gradient with the warmer ocean temperature. The result is high heat fluxes from the ocean to the atmosphere, destabilization of the air column and lowered SLP. Baroclinicity is also enhanced by the greater horizontal temperature contrast between land and open ocean during autumn.

Both models also indicate increase in SLP over the North Atlantic Ocean, although more significant in September (Fig. 10). Moreover, they both indicate raised pressures over most of the North Pacific Ocean, with the exception being CCSM in December (Fig. 10). However, due to the significant SLP reduction around the Sea of Okhotsk, especially in December (Fig. 10c and d), the average midlatitude changes are negligible (Table 2).

The patterns in Fig. 10 bear resemblance to the positive phase of the Arctic Oscillation (AO). This is indicative of a stronger, less wavy jet stream, which steers storms eastwards to the north of their usual paths and leaves midlatitudes with fewer cold air outbreaks than usual (Thompson and Wallace, 2001). As in other CMIP5 models (Barnes and Polvani, 2013), this pattern is more marked in the North Atlantic compared to the North Pacific sector in NorESM and CCSM.

\subsubsection{Track density}

The variability in the North Pacific storm track severely determines the day-to-day weather conditions downstream in the coastal regions of western Canada and southern Alaska. The same can be said of the North Sea region from the North Atlantic storm track, both regions represented by wet and stormy climates in Figs. 7a, 8a and 9a. This feature explains the choice of regions shown in Fig. 11a. Some earlier studies have indicated poleward shifts of the two main storm tracks in a warmer climate (e.g. Bengtsson et al., 2006, 2009; Fischer-Bruns et al., 2005). If this also holds for NorESM and CCSM, we would expect to see track density reductions in WNA and NWE with corresponding enhancements in BWA and NEE. However, Table 3 shows no clear indications of these shifts.

According to NorESM and CCSM, fewer cyclones will track along the current main storm tracks in the North Atlantic and North Pacific oceans towards the end of the century (Fig. 11). This explains the 3.9\% (NorESM) to $6.5 \%$ (CCSM) reductions in midlatitudes found in Table 2 (for

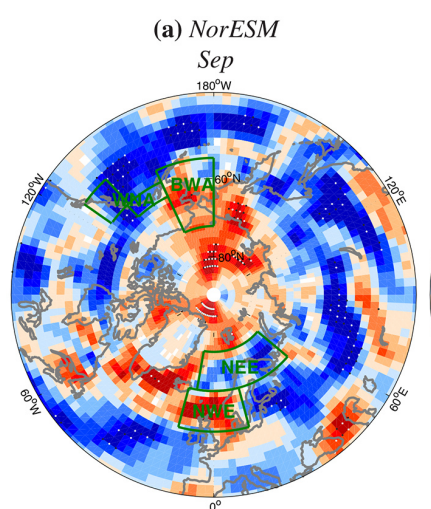

(c) NorESM

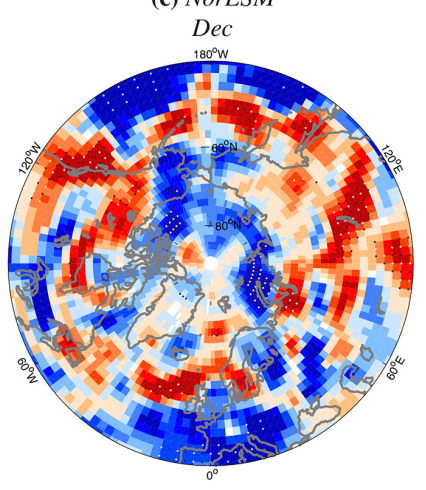

No. dens (month $)^{-1}\left(10^{6} \mathrm{~km}^{2}\right)^{-1}$

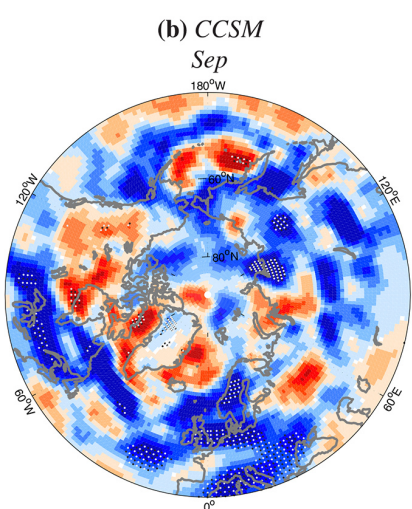

(d) $C C S M$

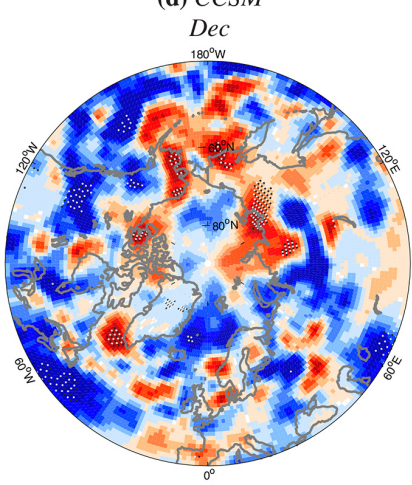

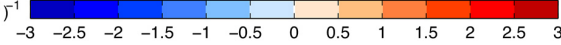

Figure 11. Changes in track density averages for September (upper row) and December (lower row) 2074-2100 compared to 19792005 following the RCP8.5 scenario in (a, c) NorESM and (b, d) CCSM. Alternating black and white dots mark regions where $p<0.05$ based on 2000 samples. Green boxes in panel (a) show the four regions in Table 3.

SOND), with up to $20.1 \%$ (NorESM) and $21.7 \%$ (CCSM) drops in WNA and NWE activity, respectively (Table 3; both for September). On the other hand, there are signals partly indicating more cyclones poleward of this in the two models in Fig. 11.

The general reduction in North Pacific cyclones is associated with more cyclones in parts of the Bering Sea (Fig. 11). However, no consistent tendency is found for the two models and two months, explaining the highly varying changes for BWA in Table 3 (from $-13.4 \%$ in NorESM to $+15.5 \%$ in CCSM, both for December). A comparison to Harvey et al. (2015) reveals that this signal of a poleward shift of the North Pacific storm track was more apparent in CMIP3 models.

NorESM projects a stronger northward shift than CCSM in the North Pacific sector (Fig. 11a and c compared to Fig. 11b and d), although December averages within the chosen regions suggests the opposite $(+18.2 \%$ in WNA, $-13.4 \%$ in BWA; Table 3). While NorESM indicates more cyclones to track through the Bering Strait and into the Arctic Ocean in September, a more zonal pattern is projected in the North Pacific Ocean for December, with a significant track density 
increase in a band around $50^{\circ} \mathrm{N}$ (Fig. 11a and c). This pattern is not found in CCSM (Fig. 11b and d), which rather projects strong increases along the North American and Siberian Arctic coasts in December (Fig. 11d). The latter feature is mostly a consequence of coinciding enhanced cyclone genesis (not shown).

Fewer cyclones track across the North Atlantic Ocean overall in both months and models (Fig. 11). NorESM, like the majority of CMIP5 models (Feser et al., 2015, and references therein), project an eastward extension of the North Atlantic storm track (Fig. 11a and c). This evolution occurs downstream of an already too zonal storm track compared to the reanalysis (Fig. 7b), with a $10.2 \%$ (December) to $12.8 \%$ (September) increase in NWE (Table 3). CCSM also represents the North Atlantic storm track too zonal originally (Fig. 7c), but projects no clear indications of a more zonal storm track towards the end of the 21 st century $(-21.7 \%$ for September to $+1.2 \%$ for December over NWE in Table 3).

No significant changes are found in NEE (Table 3 and Fig. 11a and c). Rather, both NorESM and CCSM show weak reductions in NEE track density $(-11.6 \%$ in CCSM to $-0.8 \%$ in NorESM; Table 3 ) associated with enhancements in the Greenland Sea in September (Fig. 11a and b). Figure 1 reveals that the latter increase coincides with a sea ice retreat in the Greenland Sea over the century. These results follow those of Deser et al. (2000), Magnusdottir et al. (2004) and Knudsen et al. (2015), who found storm activity to be very sensitive to the sea ice variations east of Greenland. Moreover, Chen et al. (2015) showed a corresponding sensitivity in synoptic activity here associated with variations in the surface mass balance of the Greenland Ice Sheet.

Corresponding to the observed trend found by Sepp and Jaagus (2011), the raised number of cyclones tracking through the Greenland Sea coincides with an increase also in the Labrador Sea and Baffin Bay. While the additional cyclones in these regions are short-lived in CCSM (not shown), they continue polewards (not shown) and add to the projected Arctic Ocean cyclonic activity increase from the Pacific sector in NorESM (Fig. 11a). Nevertheless, this Arctic enhancement is found in September for NorESM alone, and the highlatitude circumglobal changes over the whole season in both models are negligible $(-0.8$ to $+0.3 \%$; Table 2$)$. This contrasts Harvey et al. (2015), who found a significant decrease in high-latitude storm activity with retreating sea ice edge, thus highlighting the complex interconnections determining synoptic changes in a warmer climate system.

Numerous reanalysis studies have shown tendencies of poleward-shifted storm tracks in both the North Atlantic and North Pacific oceans over time (e.g. McCabe et al., 2001; Wang et al., 2006; Sepp and Jaagus, 2011; Wang et al., 2013). Here, only December projections in NorESM resemble similar results. Rather, the general picture of the two main storm tracks in Fig. 11 is more in line with more recent results (e.g. Zappa et al., 2013b; Harvey et al., 2015), with indications of a poleward-shifted North Pacific storm track and eastwardelongated North Atlantic storm track.

\subsubsection{Mean intensity}

Towards the end of the century, cyclones are generally projected to weaken over midlatitudes (including the main storm tracks) and strengthen over high latitudes (Table 2 and Fig. 12). This corresponds to the overall picture in Fig. 11, although the high-latitude amplification is clearer for intensities (Table 2). On the other hand, the weakening in midlatitudes is smaller, with an average $2 \%$ reduction in mean intensity over the domain of the two models compared to $4 \%$ decrease in track density. In other words, while there is a projected decrease in the number of storms crossing the North Atlantic and the North Pacific oceans, their strength will not drop proportionally. This result illustrates the lack of linear relationships between storm intensities and frequencies. It is consistent with the projections of tropical cyclone activity in Stocker et al. (2013), characterized by an increase in global mean maximum wind speed, but by either a decrease or no change in the global frequency.

The results discussed here support the findings of McCabe et al. (2001). They found an insignificant increasing historical trend in winter storm intensity on top of a significant decrease in cyclone frequency over midlatitudes. Moreover, using BCM, Orsolini and Sorteberg (2009) projected a 3.1 to $4.6 \%$ drop in the total number of summer cyclones in the $\mathrm{NH}$ over the century, but also saw a slight storm intensification in high latitudes.

For September, both NorESM and CCSM project a significant increase in cyclone strength over the Arctic Ocean (Fig. 12a and b). By the end of the century, the Arctic is essentially ice-free by September in NorESM and CCSM (Table 1 and green lines in Fig. 12a and b). Hence, as the atmosphere cools off more rapidly than the ocean in autumn, strong vertical gradients of temperature and moisture arise. Heat fluxes enter the atmosphere, destabilize the air column and thus promote cyclogenesis. Additionally, the enhanced latent heat release and reduced friction (and low-level convergence) due to the sea ice melt might also intensify the cyclones. This intensification might account in part for the SLP deepening over the Arctic seen in Table 2 and Fig. 10. Stronger cyclones have lower SLP, and this tendency is consistent with the observational results of Sepp and Jaagus (2011).

The heat flux potential is even stronger in December when the temperature gradient between the ocean and the atmosphere is greater. As a result, the future time period icefree areas of the Sea of Okhotsk, Bering and Chukchi seas are projected to be characterized by more intense cyclones (Fig. 12c and d). However, only minor changes are found along the Atlantic sea ice edge, and NorESM also indicates a significant decrease in cyclone strength over most of the Arctic Ocean (Fig. 12c). The latter feature is most likely a 


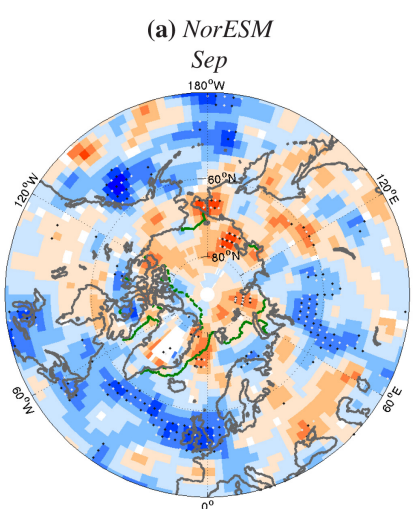

(c) NorESM

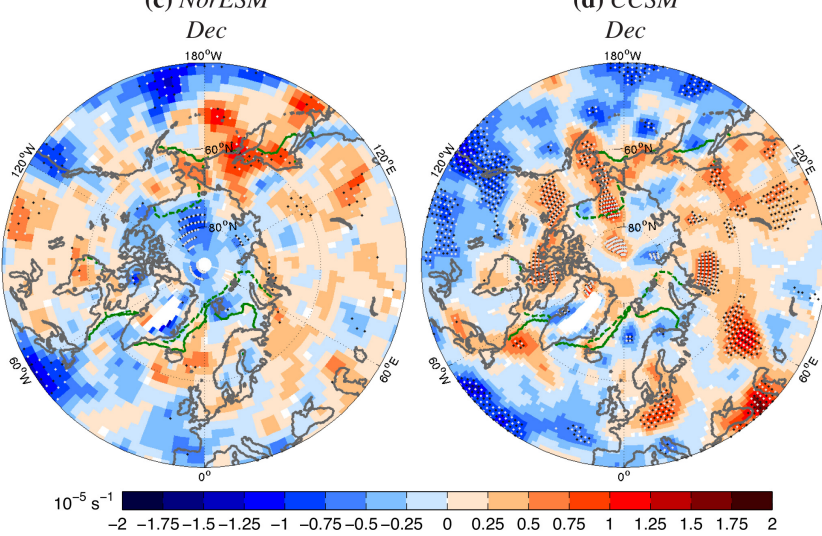

Figure 12. Changes in mean intensity averages for September (upper row) and December (lower row) 2074-2100 compared to 1979-2005 following the RCP8.5 scenario in (a, c) NorESM and (b, d) CCSM. Regions with track density below 0.5 no. density (month) $)^{-1}\left(10^{6} \mathrm{~km}^{2}\right)^{-1}$ in the historical time period are shaded white. Alternating black and white dots mark regions where $p<$ 0.05 based on 2000 samples. Solid and dashed green lines show the sea ice boundaries in each model and month over 1979-2005 and RCP8.5 2074-2100, respectively, calculated using a threshold of $15 \%$ SIC.

result of the significant reduction of the number of cyclones (Fig. 11c). Conversely, in the rapidly winter-warming Russian sector (Stocker et al., 2013), cyclones are projected to become more intense (Fig. 12c and d) and, in NorESM, also more numerous (Fig. 11c).

According to the two models, cyclones generally weaken in WNA $(-6.2 \%$ for September to $0 \%$ for December, both in NorESM) and strengthen in BWA $(-1.4 \%$ in NorESM for September to $+8.3 \%$ in CCSM for December; Table 3 and Fig. 12). This mainly follows from the poleward-shifted storm track and track density pattern discussed in Sect. 3.3.2, although the negligible change in cyclone intensity starkly contrasts the $18.2 \%$ increase in cyclone frequency in WNA for December in NorESM (Table 3) - especially if one would have expanded the region southward. In the coastal regions from Oregon to British Columbia, the number of cyclones significantly increases while their strength significantly de- creases (Fig. 11c compared to Fig. 12c). The opposite holds true in BWA (Table 3), demonstrating the closer resemblance between the two models for mean intensity than track density.

The projected changes in cyclone frequency and intensity along the North American west coast extend the results of Vose et al. (2014). Along this coast, they found a tendency of enhanced cyclonic activity (number and intensity) in the American sector and reduced activity in the Canadian sector over 1979-2010 compared to 1948-1978 during the cold season. These tendencies coincided with raised wave heights from the Baja California peninsula to the Aleutian Islands, emphasizing the importance of correct cyclone projections with regards to flooding, erosion and coastal activities.

In NWE, cyclones weaken by $5.9 \%$ (NorESM) to $8.9 \%$ (CCSM) in September and intensify by $1.3 \%$ (CCSM) to $4.2 \%$ (NorESM) in December (Table 3). The signal for NEE is less clear, although the changes for the continental areas of the region seem to be anticorrelated with the corresponding continental changes in NWE (Fig. 12).

Bengtsson et al. $(2006,2009)$ found that storms are likely to become less frequent and less intense at midlatitudes, but more numerous and stronger at high latitudes by the late $21 \mathrm{st}$ century compared to the late 20th century. Although mainly focusing on the winter (DJF) and summer (JJA) seasons, the $\mathrm{NH}$-averaged signal was also apparent in the autumn (SON) season. Our results in Figs. 11 and 12 strengthen this conclusion.

\subsubsection{Precipitation}

Both models project significantly wetter conditions in high latitudes by the end of the century compared to the historical time period, with the SOND mean rising $31.8 \%$ (CCSM) to $38.2 \%$ (NorESM; Table 2). As seen in Fig. 13, this applies to both September and December. However, differences between September and December are apparent in midlatitudes. While there is an overall increase also here $8.0 \%$ in CCSM to 10.7 in NorESM; Table 2), large areas of reduced precipitation occur in September (Fig. 13a and b). These are mainly the eastern North Pacific and North Atlantic oceans, the latter giving most of Europe drier conditions by the end of the century.

The reduced precipitation in the eastern North Atlantic Ocean in September coincides with reduced cyclone frequency in CCSM and intensity in both NorESM and CCSM (Fig. 13a and b compared to Figs. 11b, 12a and b). The correspondence between precipitation and cyclone intensity is consistent with the findings of Zappa et al. (2013b). However, while the changes in storm tracks and precipitation are consistent, this consistency does not prove a causal relationship. The expected drying of the eastern North Atlantic Ocean stems from the poleward migration of the Hadley Cell's downward limb (Kang and Lu, 2012), which is projected to increase dryness in the African-Eurasian region 

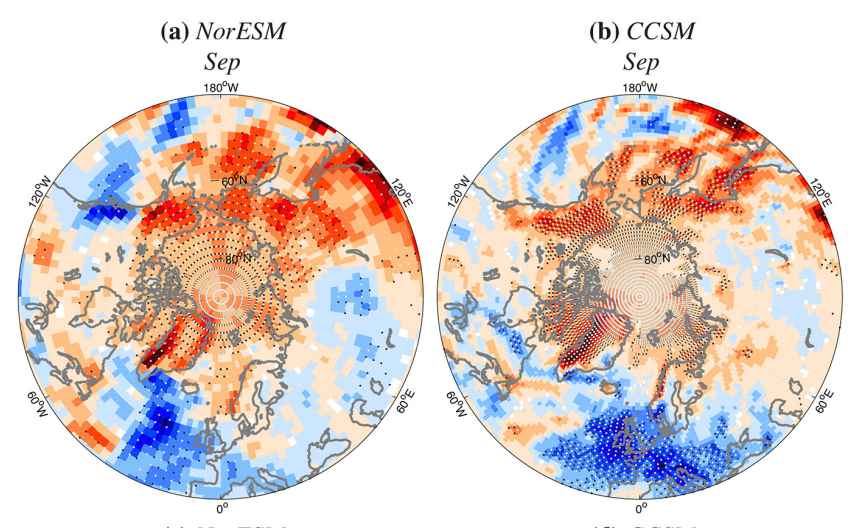

(c) NorESM

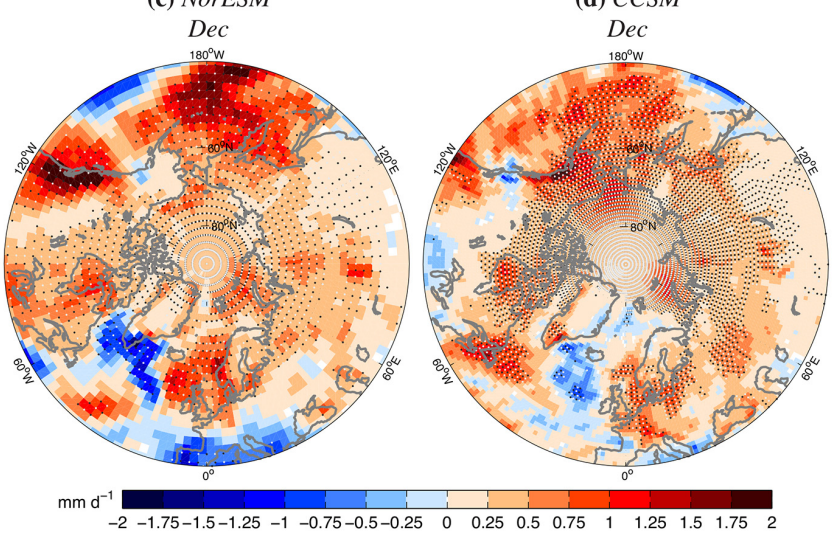

Figure 13. Changes in precipitation averages for September (upper row) and December (lower row) 2074-2100 compared to 19792005 following the RCP8.5 scenario in (a, c) NorESM and (b, d) CCSM. Alternating black and white dots mark regions of significant change at a $95 \%$ confidence level.

(including the Mediterranean), southwestern North America and northeastern Brazil (Lau and Kim, 2015). The eastern North Atlantic is projected to warm less than the rest of the $\mathrm{NH}$, with relatively lower humidity reducing the potential for increased atmospheric moisture (Stocker et al., 2013). In December, the changes of precipitation in the eastern North Atlantic are mostly positive and are not strongly related to storm track changes (Fig. 13c and d).

The largest increases in precipitation are found along the shifted main storm tracks and in regions of enhanced cyclone frequency and strength (Figs. 11, 12 and 13), in accordance with the near doubling along the cyclone tracks relative to the global mean increase found by Bengtsson et al. (2009). At the landfall of the shifted storm tracks, western Alaska and northern Scandinavia are projected to see much stormier and wetter autumns by the end of the century (Figs. 11, 12 and 13).

Compared to September, the two models predict enhanced precipitation over more of the domain in December (Fig. 13c and d). Part of the reason is that the indication of a poleward shift of the storm tracks is more significant for September than December (Sect. 3.3.2 and 3.3.3). As in Zappa et al. (2014a), the expected drier conditions in the Mediterranean region coincide with a reduction in cyclone frequency (Fig. 11 compared to Fig. 13). This is indicative of the wet-get-wetter, dry-get-drier pattern reported elsewhere (e.g. Held and Soden, 2006; Stocker et al., 2013).

The two models generally agree, but NorESM expands the wetter projection over a larger area of North America in December (Fig. 13c compared to Fig. 13d). In contrast, the pattern over Europe shows greater seasonal change in CCSM (Fig. 13d compared to Fig. 13b), with a wider region of reduced precipitation than in NorESM for September (Fig. 13b compared to Fig. 13a) and a wider region of more precipitation for December (Fig. 13d compared to Fig. 13c). Averaged over the $40-90^{\circ} \mathrm{N}$ domain for SOND, the two models both project $0.3 \mathrm{~mm} \mathrm{~d}^{-1}$ more precipitation. This overall increase of precipitation is consistent with an increase of temperature and the ability of warm air to contain more moisture, resulting in an acceleration of the hydrologic cycle (Held and Soden, 2006).

Of the four regions, 2 months and two models in Table 3, only Septembers over the WNA region in NorESM and over the NWE region in CCSM are projected to become drier (4.1 and $12.0 \%$, respectively). However, compared to the significant increase in precipitation over the domain (Table 2 and Fig. 13a and b), the September 5.8 and $5.7 \%$ increases in WNA in CCSM and NWE in NorESM, respectively, are also relatively small (Table 3). Again, the poleward-shifted North Pacific and North Atlantic storm tracks are likely causes, leaving September in the more northern BWA 18.0\% (CCSM) to $23.8 \%$ (NorESM) wetter and NEE wetter by $11.7 \%$ (NorESM) to $13.0 \%$ (CCSM) (Table 3 and Figs. 11a, $\mathrm{b}$ and 13a, b). More cyclones in the Bering, North and Greenland seas partly explain the significant increase in precipitation over the continental area to their east: Alaska, southern and northern Norway (Figs. 11a, b and 13a, b).

In December, the poleward storm track shift is less significant (Fig. 11c and d), giving $10.1 \%$ (CCSM) to $15.5 \%$ (NorESM) more precipitation in WNA and $8.7 \%$ (CCSM) to $19.7 \%$ (NorESM) in NWE (Table 3 and Fig. 13c and d). The models still project significantly wetter conditions in BWA and NEE (although with an exception of NEE in CCSM; Fig. 13d), highlighting the increased availability of warmer air to hold moisture in the most rapidly warming region and season (Stocker et al., 2013).

Totalled over the full season SOND, the projected changes in precipitation in Fig. 13 might have severe consequences for multiple regions. Two of these are the Norwegian west coast (here defined $58-63^{\circ} \mathrm{N}, 5.0-7.5^{\circ} \mathrm{E}$ ) and the Gulf of Alaska (here defined $58-63^{\circ} \mathrm{N}, 135-155^{\circ} \mathrm{W}$ ). They are currently among the wettest regions in the extratropical $\mathrm{NH}$. If we would believe the RCP8.5 projections from the models, an additional $40 \mathrm{~mm}(+5.0 \%$; CCSM) to $133 \mathrm{~mm}$ $(+24.1 \%$; NorESM $)$ and $71 \mathrm{~mm}(+15.9 \%$; NorESM $)$ to $115 \mathrm{~mm}(+21.0 \%$; CCSM) precipitation will fall over the Norwegian west coast and the Gulf of Alaska, respectively, 
over each SOND season during the years 2074-2100 compared to 1979-2005.

\section{Conclusions}

In this study, we have used a vorticity-based storm-tracking algorithm to analyse changes in metrics of storminess in high and midlatitudes through 2100 in the NorESM1-M global climate model. The main findings obtained from NorESM1$\mathrm{M}$ are generally supported by the results obtained from a second model, CCSM4, which was examined for comparison purposes. The two models were also compared to the reanalysis data set ERA-Interim for the historical time period. Results are based on only one ensemble member for each model due to data availability.

The primary findings include the following:

- For the two models (with one ensemble member each), the projected changes in storm intensity, sea ice, sea level pressure (SLP) and precipitation all appear to scale generally linearly with the RCP value of the forcing scenario. The changes in these variables also appear to be generally linear functions of time through the 21 st century.

- A significant projected decrease of the SLP over the Arctic Ocean during the 21st century appears to be partly a consequence of the diminishing sea ice cover on the same timescales. These changes are consistent with increased heating of the lower troposphere over areas of sea ice loss, resulting in increased thicknesses in the lower troposphere, and increased geopotential heights and mass divergence aloft. Accordingly, SLP values are projected to decrease over the Arctic Ocean and increase farther south, significantly over the North Atlantic Ocean, coinciding with reduced midlatitude storm track activity.

- Cyclones are generally expected to weaken over midlatitudes and strengthen over high latitudes, although this is more apparent for September than December. The intensification is especially marked in areas of sea ice retreat, where heat fluxes into the atmosphere, latent heat release and reduced friction promote cyclogenesis.

- Projected changes in track density are much less coherent, although there is a general tendency towards less frequent storms in midlatitudes and more frequent storms in certain regions at high latitudes. Relatively large increases in frequency are projected locally for the Baffin Bay/Davis Strait region in September.

- Over the whole domain circumpolar north of $40^{\circ} \mathrm{N}$, there is a tendency of slightly fewer and weaker cyclones towards the end of the century. However, the reduction in frequency ( $4 \%$ ) is larger than intensity $(2 \%)$, indicating that changes in cyclone strength do not correspond directly to changes in cyclone frequency.

- Autumn precipitation is projected to increase significantly across the entire high latitudes. Together with the projected loss of sea ice and increases in storm intensity and sea level, this increase implies a greater vulnerability to coastal flooding and erosion, especially in the Alaskan region.

- The models reproduce the observed seasonality of the sea ice loss and the general patterns of SLP and cyclone metrics, although the storm tracks (densities) and intensities are somewhat less sharp relative to ERA-I because of the coarser resolution in the models. The ongoing (observed) and projected (modelled) retreat of sea ice is greatest in autumn, creating the potential for increased fluxes of sensible and latent heat from the surface to the atmosphere during these months.

The results reported here are limited to two climate models and to two simulations by each model, one with a low emission scenario (RCP 4.5) and one with a high (businessas-usual) scenario (RCP 8.5). The projected changes appear to scale linearly with the intensity of the RCP forcing. The robustness of such results obtained would be enhanced by the inclusion of additional models and ensemble members. However, the results obtained from the two different models show enough similarities that the conclusions listed above can be taken as starting points in assessments of the likely changes in storm activity in the northern high latitudes.

As additional models and ensemble members are included in assessments of future changes in Arctic cyclone activity, the relative importance of internal variability (deduced from different ensemble members of a single model) and modelderived uncertainty (deduced from across-model differences in cyclone statistics) will be important to an assessment of uncertainties. Should across-model differences dominate (as they do with temperature, for example), priority must be given to diagnosing the reasons why the models are different. It may also be fruitful to explore model selection ("filtering") strategies based on the fidelity of the models to the observed data on cyclone activity.

Storm frequency, intensity and precipitation changes are likely to have costly impacts on human society, especially on top of sea level rise. This adds to the importance of reducing the uncertainties in future changes of Arctic cyclone activity and related variables that will impact northern coasts, communities and offshore activities.

\section{Data availability}

The data for this paper are available at the CMIP5 web page by the Program for Climate Model Diagnosis and Intercomparison (World Climate Research Programme's Working 
Group on Coupled Modelling, 2013) and at the ERA-I web access by ECMWF (European Centre for Medium-Range Weather Forecasts, 2014).

Author contributions. The authors shared the task of designing and evaluating the study, while E. M. Knudsen carried out the data acquisition and analysis. E. M. Knudsen also prepared the manuscript, but with significant contributions from J. E. Walsh.

Acknowledgements. We thank K. I. Hodges for providing the TRACK algorithm and guidance on $p$ value calculations for the storm track parameters. We are grateful to A. Sorteberg for his helpful internal review of an earlier version of this manuscript. We also wish to thank the two anonymous reviewers, who provided constructive suggestions that significantly improved the manuscript. The work was financially supported by the Research Council of Norway through the BlueArc project (no. 207650) and by the U.S. National Science Foundation through Grants ARC-1023131 and ARC-1049225.

Edited by: R. Marsh

\section{References}

AMAP: Arctic Climate Impact Assessment (ACIA), Tech. rep., Arctic Monitoring and Assessment Programme (AMAP), New York, USA, 2005.

AMAP: Snow, water, ice and permafrost in the Arctic (SWIPA): Climate change and the cryosphere, Tech. rep., Arctic Monitoring and Assessment Programme (AMAP), Oslo, Norway, 2011.

Barnes, E.: Revisiting the evidence linking Arctic amplification to extreme weather in midlatitudes, Geophys. Res. Lett., 40, 4734 4739, doi:10.1002/grl.50880, 2013.

Barnes, E. and Polvani, L.: Response of the midlatitude jets, and of their variability, to increased greenhouse gases in the CMIP5 models, J. Climate, 26, 7117-7135, doi:10.1175/JCLI-D-1200536.1, 2013.

Barnes, E. and Screen, J.: The impact of Arctic warming on the midlatitude jet-stream: Can it? Has it? Will it?, WIREs Clim. Change, 6, 277-286, doi:10.1002/wcc.337, 2015.

Barnes, E., Dunn-Sigouin, E., Masato, G., and Woollings, T.: Exploring recent trends in Northern Hemisphere blocking, Geophys. Res. Lett., 41, 638-644, doi:10.1002/2013GL058745, 2014.

Bekryaev, R., Polyakov, I., and Alexeev, V.: Role of polar amplification in long-term surface air temperature variations and modern Arctic warming, J. Climate, 23, 3888-3906, doi:10.1175/2010JCLI3297.1, 2010.

Bengtsson, L., Hodges, K., and Roeckner, E.: Storm tracks and climate change, J. Climate, 19, 3518-3543, doi:10.1175/JCLI3815.1, 2006.

Bengtsson, L., Hodges, K., and Keenlyside, N.: Will extratropical storms intensify in a warmer climate?, J. Climate, 22, 22762301, doi:10.1175/2008JCLI2678.1, 2009.
Bentsen, M., Bethke, I., Debernard, J. B., Iversen, T., Kirkevåg, A., Seland, Ø., Drange, H., Roelandt, C., Seierstad, I. A., Hoose, C., and Kristjánsson, J. E.: The Norwegian Earth System Model, NorESM1-M - Part 1: Description and basic evaluation of the physical climate, Geosci. Model Dev., 6, 687-720, doi:10.5194/gmd-6-687-2013, 2013.

Bleck, R., Rooth, C., Hu, D., and Smith, L.: Salinity-driven thermocline transients in a wind- and thermohalineforced isopycnic coordinate model of the North Atlantic, J. Phys. Oceanogr., 22, 1486-1505, doi:10.1175/15200485(1992)022<1486:SDTTIA>2.0.CO;2, 1992.

Bracegirdle, T. and Gray, S.: An objective climatology of the dynamical forcing of polar lows in the Nordic Seas, Int. J. Climatol., 28, 1903-1919, doi:10.1002/joc.1686, 2008.

Catto, J., Shaffrey, L., and Hodges, K.: Northern Hemisphere extratropical cyclones in a warming climate in the HiGEM high-resolution climate model, J. Climate, 24, 5336-5352, doi:10.1175/2011JCLI4181.1, 2011.

Catto, J., Jakob, C., Berry, G., and Nicholls, N.: Relating global precipitation to atmospheric fronts, Geophys. Res. Lett., 39, L10805, doi:10.1029/2012GL051736, 2012.

Catto, J., Jakob, C., and Nicholls, N.: A global evaluation of fronts and precipitation in the ACCESS model, Aust. Meteorol. Ocean. Soc. J., 63, 191-203, 2013.

Catto, J., Jakob, C., and Nicholls, N.: Can the CMIP5 models represent winter frontal precipitation?, Geophys. Res. Lett., 42, 85968604, doi:10.1002/2015GL066015, 2015.

Chen, L., Fettweis, X., Knudsen, E., and Johannessen, O.: Impact of cyclonic and anticyclonic activity on Greenland ice sheet surface mass balance variation during 1980-2013, Int. J. Climatol., doi:10.1002/joc.4565, 2015.

Chung, C. E., Cha, H., Vihma, T., Räisänen, P., and Decremer, D.: On the possibilities to use atmospheric reanalyses to evaluate the warming structure in the Arctic, Atmos. Chem. Phys., 13, 11209 11219, doi:10.5194/acp-13-11209-2013, 2013.

Cohen, J., Furtado, J., Barlow, M., Alexeev, V., and Cherry, J.: Arctic warming, increasing snow cover and widespread boreal winter cooling, Environ. Res. Lett., 7, 014007, doi:10.1088/17489326/7/1/014007, 2012.

Condron, A. and Renfrew, I.: The impact of polar mesoscale storms on northeast Atlantic Ocean circulation, Nat. Geosci., 6, 34-37, doi:10.1038/ngeo1661, 2013.

Condron, A., Bigg, G., and Renfrew, I.: Polar mesoscale cyclones in the northeast Atlantic: Comparing climatologies from ERA40 and satellite imagery, Mon. Weather Rev., 134, 1518-1533, doi:10.1175/MWR3136.1, 2006.

de Boer, G., Chapman, W., Kay, J., Medeiros, B., Shupe, M., Vavrus, S., and Walsh, J.: A characterization of the presentday Arctic atmosphere in CCSM4, J. Climate, 25, 2676-2695, doi:10.1175/JCLI-D-11-00228.1, 2012.

Dee, D., Uppala, S., Simmons, A., Berrisford, P., Poli, P., Kobayashi, S., Andrae, U., Balmaseda, M., Balsamo, G., Bauer, P., Bechtold, P., Beljaars, A., van de Berg, L., Bidlot, J., Bormann, N., Delsol, C., Dragani, R., Fuentes, M., Geer, A., Haimberger, L., Healy, S., Hersbach, H., Hólm, E., Isaksen, L., Kållberg, P., Köhler, M., Matricardi, M., McNally, A., MongeSanz, B., Morcrette, J.-J., Park, B.-K., Peubey, C., de Rosnay, P., Tavolato, C., Thépaut, J.-N., and Vitart, F.: The ERAInterim reanalysis: Configuration and performance of the data 
assimilation system, Q. J. Roy. Meteor. Soc., 137, 553-597, doi:10.1002/qj.828, 2011.

Deser, C., Walsh, J., and Timlin, M.: Arctic sea ice variability in the context of recent atmospheric circulation trends, J. Climate, 13, 617-633, doi:10.1175/15200442(2000)013<0617:ASIVIT>2.0.CO;2, 2000

DeWeaver, E. and Bitz, C.: Atmospheric circulation and its effect on Arctic sea ice in CCSM3 simulations at medium and high resolution, J. Climate, 19, 2415-2436, doi:10.1175/JCLI3753.1, 2006.

Drange, H., Gerdes, R., Gao, Y., Karcher, M., Kauker, F., and Bentsen, M.: Ocean general circulation modelling of the Nordic Seas, in: The Nordic Seas: An integrated perspective, edited by: Drange, H., Dokken, T., Furevik, T., Gerdes, R., and Berger, W., vol. 158, 199-219, Wiley Online Library, Washington D.C., USA, 2005.

European Centre for Medium-Range Weather Forecasts: ERA Interim, Monthly Means of Daily Means, available at: http://apps. ecmwf.int/datasets/data/interim-full-moda/levtype $=\mathrm{sfc} /$, last access: 1 July 2014.

Feser, F., Barcikowska, M., Krueger, O., Schenk, F., Weisse, R., and Xia, L.: Storminess over the North Atlantic and northwestern Europe - A review, Q. J. Roy. Meteor. Soc., 141, 350-382, doi:10.1002/qj.2364, 2015.

Fetterer, F., Knowles, K., Meier, W., and Savoie, M.: Sea Ice Index, Version 1, digital media, doi:10.7265/N5QJ7F7W (updated daily, last access: 30 January 2015), 2002.

Fischer-Bruns, I., von Storch, H., González-Rouco, J., and Zorita, E.: Modelling the variability of midlatitude storm activity on decadal to century time scales, Clim. Dynam., 25, 461-476, doi:10.1007/s00382-005-0036-1, 2005.

Francis, J. and Vavrus, S.: Evidence linking Arctic amplification to extreme weather in mid-latitudes, Geophys. Res. Lett., 39, L06801, doi:10.1029/2012GL051000, 2012.

Furevik, T., Bentsen, M., Drange, H., Kindem, I., Kvamst $\varnothing$, N., and Sorteberg, A.: Description and evaluation of the Bergen climate model: ARPEGE coupled with MICOM, Clim. Dynam., 21, 2751, doi:10.1007/s00382-003-0317-5, 2003.

Gent, P., Danabasoglu, G., Donner, L., Holland, M., Hunke, E., Jayne, S., Lawrence, D., Neale, R., Rasch, P., Vertenstein, M., Worley, P., Yang, Z.-L., and Zhang, M.: The Community Climate System Model version 4, J. Climate, 24, 4973-4991, doi:10.1175/2011JCLI4083.1, 2011.

Harvey, B., Shaffrey, L., and Woollings, T.: Deconstructing the climate change response of the Northern Hemisphere wintertime storm tracks, Clim. Dynam., 45, 2847-2860, doi:10.1007/s00382-015-2510-8, 2015.

Hawcroft, M., Shaffrey, L., Hodges, K., and Dacre, H.: How much Northern Hemisphere precipitation is associated with extratropical cyclones?, Geophys. Res. Lett., 39, L24809, doi:10.1029/2012GL053866, 2012.

Held, I. and Soden, B.: Robust responses of the hydrological cycle to global warming, J. Climate, 19, 5686-5699, doi:10.1175/JCLI3990.1, 2006.

Hodges, K.: A general method for tracking analysis and its application to meteorological data, Mon. Weather Rev., 122, 2573-2586, doi:10.1175/1520-0493(1994)122<2573:AGMFTA>2.0.CO;2, 1994.
Hodges, K.: Feature tracking on the unit-sphere, Mon. Weather Rev., 123, 3458-3465, doi:10.1175/15200493(1995)123<3458:FTOTUS>2.0.CO;2, 1995.

Hodges, K.: Spherical nonparametric estimators applied to the UGAMP model integration for AMIP, Mon. Weather Rev., 124, 2914-2932, doi:10.1175/15200493(1996)124<2914:SNEATT>2.0.CO;2, 1996.

Hodges, K.: Adaptive constraints for feature tracking, Mon. Weather Rev., 127, 1362-1373, doi:10.1175/15200493(1999)127<1362:ACFFT>2.0.CO;2, 1999.

Hodges, K.: Confidence intervals and significance tests for spherical data derived from feature tracking, Mon. Weather Rev., 136, 1758-1777, doi:10.1175/2007MWR2299.1, 2008.

Hodges, K., Hoskins, B., Boyle, J., and Thorncroft, C.: A comparison of recent reanalysis datasets using objective feature tracking: Storm tracks and tropical easterly waves, Mon. Weather Rev., 131, 2012-2037, doi:10.1175/15200493(2003)131<2012:ACORRD>2.0.CO;2, 2003.

Hodges, K., Lee, R., and Bengtsson, L.: A comparison of extratropical cyclones in recent reanalyses ERA-Interim, NASA MERRA, NCEP CFSR, and JRA-25, J. Climate, 24, 4888-4906, doi:10.1175/2011JCLI4097.1, 2011.

Iversen, T., Bentsen, M., Bethke, I., Debernard, J. B., Kirkevåg, A., Seland, Ø., Drange, H., Kristjansson, J. E., Medhaug, I., Sand, M., and Seierstad, I. A.: The Norwegian Earth System Model, NorESM1-M - Part 2: Climate response and scenario projections, Geosci. Model Dev., 6, 389-415, doi:10.5194/gmd-6-3892013, 2013.

Jakobson, E., Vihma, T., Palo, T., Jakobson, L., Keernik, H., and Jaagus, J.: Validation of atmospheric reanalyses over the central Arctic Ocean, Geophys. Res. Lett., 39, L10802, doi:10.1029/2012GL051591, 2012.

Kang, S. and Lu, J.: Expansion of the Hadley cell under global warming: Winter versus summer, J. Climate, 25, 8387-8393, doi:10.1175/JCLI-D-12-00323.1, 2012.

Karl, T., Melillo, J., and Peterson, T. (Eds.): Global climate change impacts in the United States, Tech. rep., U.S. Global Change Research Program (USGRP), Cambridge, UK and New York, USA, 2009.

Kirkevåg, A., Iversen, T., Seland, Ø., Hoose, C., Kristjánsson, J. E., Struthers, H., Ekman, A. M. L., Ghan, S., Griesfeller, J., Nilsson, E. D., and Schulz, M.: Aerosol-climate interactions in the Norwegian Earth System Model - NorESM1-M, Geosci. Model Dev., 6, 207-244, doi:10.5194/gmd-6-207-2013, 2013.

Knudsen, E., Orsolini, Y., Furevik, T., and Hodges, K.: Observed anomalous atmospheric patterns in summers of unusual Arctic sea ice melt, J. Geophys. Res.-Atmos., 120, 2595-2611, doi:10.1002/2014JD022608, 2015.

Kunkel, K., Easterling, D., Kristovich, D., Gleason, B., Stoecker, L., and Smith, R.: Meteorological causes of the secular variations in observed extreme precipitation events for the conterminous United States, J. Hydrometeorology, 13, 1131-1141, doi:10.1175/JHM-D-11-0108.1, 2012.

Kuo, Y.-H., Shapiro, M., and Donall, E.: The interaction between baroclinic and diabatic processes in a numerical simulation of a rapidly intensifying extratropical marine cyclone, Mon. Weather Rev., 119, 368-384, doi:10.1175/15200493(1991)119<0368:TIBBAD>2.0.CO;2, 1991. 
Langehaug, H., Geyer, F., Smedsrud, L., and Gao, Y.: Arctic sea ice decline and ice export in the CMIP5 historical simulations, Ocean Model., 71, 114-126, doi:10.1016/j.ocemod.2012.12.006, 2013.

Lau, W. and Kim, K.-M.: Robust Hadley Circulation changes and increasing global dryness due to $\mathrm{CO}_{2}$ warming from CMIP5 model projections, P. Natl. Acad. Sci. USA, 112, 3630-3635, doi:10.1073/pnas.1418682112, 2015.

Long, Z. and Perrie, W.: Air-sea interactions during an Arctic storm, J. Geophys. Res.-Atmos., 117, D15103, doi:10.1029/2011JD016985, 2012.

Lynch, A., Cassano, E., Cassano, J., and Lestak, L.: Case studies of high wind events in Barrow, Alaska: Climatological context and development processes, Mon. Weather Rev., 131, 719-732, doi:10.1175/1520-0493(2003)131<0719:CSOHWE >2.0.CO;2, 2003.

Magnusdottir, G., Deser, C., and Saravanan, R.: The effects of North Atlantic SST and sea ice anomalies on the winter circulation in CCM3. Part I: Main features and storm track characteristics of the response, J. Climate, 17, 857-876, doi:10.1175/15200442(2004)017<0857:TEONAS>2.0.CO;2, 2004.

Maier-Reimer, E.: Geochemical cycles in an ocean general circulation model. Preindustrial tracer distributions, Global Biogeochem. Cy., 7, 645-677, doi:10.1029/93GB01355, 1993.

Maier-Reimer, E., Kriest, I., Segschneider, J., and Wetzel, P.: The HAMburg Ocean Carbon Cycle Model HAMOCC 5.1 - Technical description release 1.1, Tech. rep., Max Planck Institute for Meteorology, Hamburg, Germany, 2005.

McCabe, G., Clark, M., and Serreze, M.: Trends in Northern Hemisphere surface cyclone frequency and intensity, J. Climate, 14, 2763-2768, doi:10.1175/15200442(2001)014<2763:TINHSC>2.0.CO;2, 2001.

Melillo, J., Richmond, T., and Yohe, G. (Eds.): Climate change impacts in the United States, Tech. rep., U.S. Global Change Research Program (USGRP), Washington D.C., USA, 2014.

Mesquita, M., Atkinson, D., and Hodges, K.: Characteristics and variability of storm tracks in the North Pacific, Bering Sea, and Alaska, J. Climate, 23, 294-311, doi:10.1175/2009JCLI3019.1, 2010.

Neu, U., Akperov, M., Bellenbaum, N., Benestad, R., Blender, R., Caballero, R., Cocozza, A., Dacre, H., Feng, Y., Fraedrich, K., Grieger, J., Gulev, S., Hanley, J., Hewson, T., Inatsu, M., Keay, K., Kew, S., Kindem, I., Leckebusch, G., Liberato, M., Lionello, P., Mokhov, I., Pinto, J., Raible, C., Reale, M., Rudeva, I., Schuster, M., Simmonds, I., Sinclair, M., Sprenger, M., Tilinina, N., Trigo, I., Ulbrich, S., Ulbrich, U., Wang, X., and Wernli, H.: IMILAST: A community effort to intercompare extratropical cyclone detection and tracking algorithms, B. Am. Meteorol. Soc., 94, 529-547, doi:10.1175/BAMS-D-11-00154.1, 2013.

O'Gorman, P. and Schneider, T.: Energy of midlatitude transient eddies in idealized simulations of changed climates, J. Climate, 21, 5797-5806, doi:10.1175/2008JCLI2099.1, 2008.

Orsolini, Y. and Sorteberg, A.: Projected changes in Eurasian and Arctic summer cyclones under global warming in the Bergen Climate Model, Atmos. Oceanic Sci. Lett., 2, 62-67, 2009.

Overland, J. and Wang, M.: Large-scale atmospheric circulation changes are associated with the recent loss of Arctic sea ice, Tellus A, 62, 1-9, doi:10.1111/j.1600-0870.2009.00421.x, 2010.
Overland, J., Wang, M., Walsh, J., and Stroeve, J.: Future Arctic climate changes: Adaptation and mitigation time scales, Earth's Future, 2, 68-74, doi:10.1002/2013EF000162, 2013.

Pinto, J., Spangehl, T., Ulbrich, U., and Speth, P.: Sensitivities of a cyclone detection and tracking algorithm: individual tracks and climatology, Meteorol. Z., 14, 823-838, doi:10.1127/09412948/2005/0068, 2005.

Pithan, F. and Mauritsen, T.: Arctic amplification dominated by temperature feedbacks in contemporary climate models, Nat. Geosci., 7, 181-184, doi:10.1038/ngeo2071, 2014.

Rogers, T. S., Walsh, J. E., Rupp, T. S., Brigham, L. W., and Sfraga, M.: Future Arctic marine access: analysis and evaluation of observations, models, and projections of sea ice, The Cryosphere, 7, 321-332, doi:10.5194/tc-7-321-2013, 2013.

Screen, J. and Simmonds, I.: Exploring links between Arctic amplification and mid-latitude weather, Geophys. Res. Lett., 40, 959964, doi:10.1002/GRL.50174, 2013.

Sepp, M. and Jaagus, J.: Changes in the activity and tracks of Arctic cyclones, Climatic Change, 105, 577-595, doi:10.1007/s10584010-9893-7, 2011.

Simmonds, I. and Keay, K.: Extraordinary September Arctic sea ice reductions and their relationships with storm behavior over 1979-2008, Geophys. Res. Lett., 36, L19715, doi:10.1029/2009GL039810, 2009.

Simmonds, I. and Rudeva, I.: The great Arctic cyclone of August 2012, Geophys. Res. Lett., 39, L23709, doi:10.1029/2012GL054259, 2012.

Sorteberg, A. and Walsh, J.: Seasonal cyclone variability at $70^{\circ} \mathrm{N}$ and its impact on moisture transport into the Arctic, Tellus A, 60, 570-586, doi:10.1111/j.1600-0870.2008.00314.x, 2008.

Stephens, G., L'Ecuyer, T., Forbes, R., Gettlemen, A., Golaz, J.C., Bodas-Salcedo, A., Suzuki, K., Gabriel, P., and Haynes, J.: Dreary state of precipitation in global models, J. Geophys. Res.Atmos., 115, D24211, doi:10.1029/2010JD014532, 2010.

Stocker, T., Qin, D., Plattner, G.-K., Tignor, M., Allen, S., Boschung, J., Nauels, A., Xia, Y., Bex, V., and Midgley, P. (Eds.): Climate change 2013: The physical science basis. Contribution of Working Group I to the Fifth Assessment Report of the Intergovernmental Panel on Climate Change, Tech. rep., Intergovernmental Panel on Climate Change (IPCC), Cambridge, UK and New York, USA, 2013.

Stroeve, J., Kattsov, V., Barrett, A., Serreze, M., Pavlova, T., Holland, M., and Meier, W.: Trends in Arctic sea ice extent from CMIP5, CMIP3 and observations, Geophys. Res. Lett., 39, L16502, doi:10.1029/2012GL052676, 2012.

Taylor, K., Stouffer, R., and Meehl, G.: An overview of CMIP5 and the experiment design, B. Am. Meteorol. Soc., 93, 485-498, doi:10.1175/BAMS-D-11-00094.1, 2012.

Thompson, D. and Wallace, J.: Regional climate impacts of the Northern Hemisphere annular mode, Science, 293, 85-89, doi:10.1126/science.1058958, 2001.

Tilinina, N., Gulev, S., and Bromwich, D.: New view of Arctic cyclone activity from the Arctic system reanalysis, Geophys. Res. Lett., 41, 1766-1772, doi:10.1002/2013GL058924, 2014.

Tjiputra, J. F., Assmann, K., Bentsen, M., Bethke, I., Otterå, O. H., Sturm, C., and Heinze, C.: Bergen Earth system model (BCM-C): model description and regional climate-carbon cycle feedbacks assessment, Geosci. Model Dev., 3, 123-141, doi:10.5194/gmd-3-123-2010, 2010. 
Trenberth, K., Jones, P., Ambenje, P., Bojariu, R., Easterling, D., Klein Tank, A., Parker, D., Rahimzadeh, F., Renwick, J., Rusticucci, M., Soden, B., and Zhai, P.: Observations: Surface and atmospheric climate change, in: Climate Change 2007: The Physical Science Basis. Contribution of Working Group I to the Fourth Assessment Report of the Intergovernmental Panel on Climate Change, Tech. rep., Intergovernmental Panel on Climate Change (IPCC), Cambridge, UK and New York, USA, 2007.

Ulbrich, U., Leckebusch, G., and Pinto, J.: Extra-tropical cyclones in the present and future climate: A review, Theor. Appl. Climatol., 96, 117-131, doi:10.1007/s00704-008-0083-8, 2009.

van Vuuren, D., Edmonds, J., Kainuma, M., Riahi, K., Thomson, A., Hibbard, K., Hurtt, G., Kram, T., Krey, V., Lamarque, J.F., Masui, T., Meinshausen, M., Nakicenovic, N., Smith, S., and Rose, S.: The representative concentration pathways: An overview, Climatic Change, 109, 5-31, doi:10.1007/s10584-0110148-z, 2011

Vose, R., Applequist, S., Bourassa, M., Pryor, S., Barthelmie, R., Blanton, B., Bromirski, P., Brooks, H., DeGaetano, A., Dole, R., Easterling, D., Jensen, R., Karl, T., Katz, R., Klink, K., Kruk, M., Kunkel, K., MacCracken, M., Peterson, T., Shein, K., Thomas, B., Walsh, J., Wang, X., Wehner, M., Wuebbles, D., and Young, R.: Monitoring and understanding changes in extremes: Extratropical storms, winds, and waves, B. Am. Meteorol. Soc., 95, 377-386, doi:10.1175/BAMS-D-12-00162.1, 2014.

Walsh, J., Chapman, W., Romanovsky, V., Christensen, J., and Stendel, M.: Global climate model performance over Alaska and Greenland, J. Climate, 21, 6156-6174, doi:10.1175/2008JCLI2163.1, 2008.

Wang, X., Swail, V., and Zwiers, F.: Climatology and changes of extratropical cyclone activity: Comparison of ERA-40 with NCEPNCAR reanalysis for 1958-2001, J. Climate, 19, 3145-3166, doi:10.1175/JCLI3781.1, 2006.

Wang, X., Feng, Y., Compo, G., Swail, V., Zwiers, F., Allan, R., and Sardeshmukh, P.: Trends and low frequency variability of extratropical cyclone activity in the ensemble of twentieth century reanalysis, Clim. Dynam., 40, 2775-2800, doi:10.1007/s00382012-1450-9, 2013.
World Climate Research Programme's Working Group on Coupled Modelling: CMIP5 - Coupled Model Intercomparison Project Phase 5 - Overview, available at: http://cmip-pcmdi.llnl.gov/ cmip5/, last access: 21 October 2013.

Yanase, W., Niino, H., Watanabe, S., Hodges, K., Zahn, M., Spengler, T., and Gurvich, I.: Climatology of polar lows over the Sea of Japan using the JRA-55 reanalysis, J. Climate, 29, 419-437, doi:10.1175/JCLI-D-15-0291.1, 2015.

Zahn, M. and von Storch, H.: A long-term climatology of North Atlantic polar lows, Geophys. Res. Lett., 35, L22702, doi:10.1029/2008GL035769, 2008.

Zappa, G., Shaffrey, L., and Hodges, K.: The ability of CMIP5 models to simulate North Atlantic extratropical cyclones, J. Climate, 26, 5379-5396, doi:10.1175/JCLI-D-12-00501.1, 2013a.

Zappa, G., Shaffrey, L., Hodges, K., Sansom, P., and Stephenson, D.: A multimodel assessment of future projections of North Atlantic and European extratropical cyclones in the CMIP5 climate models, J. Climate, 26, 5846-5862, doi:10.1175/JCLI-D12-00573.1, 2013b.

Zappa, G., Hawcroft, M., Shaffrey, L., Black, E., and Brayshaw, D.: Extratropical cyclones and the projected decline of winter Mediterranean precipitation in the CMIP5 models, Clim. Dynam., 45, 1-12, doi:10.1007/s00382-014-2426-8, 2014a.

Zappa, G., Shaffrey, L., and Hodges, K.: Can polar lows be objectively identified and tracked in the ECMWF operational analysis and the ERA-Interim reanalysis?, Mon. Weather Rev., 142, 2596-2608, doi:10.1175/MWR-D-14-00064.1, 2014b.

Zhang, X., Walsh, J., Zhang, J., Bhatt, U., and Ikeda, M.: Climatology and interannual variability of Arctic cyclone activity: 1948-2002, J. Climate, 17, 2300-2317, doi:10.1175/15200442(2004)017<2300:CAIVOA>2.0.CO;2, 2004. 